\title{
O ESTÁGIO SUPERVISIONADO NA FORMACূÃO INICIAL DE PROFESSORES: ESTADO DA ARTE DAS PESQUISAS NACIONAIS DA ÁREA DE ENSINO DE CIÊNCIAS
}

\author{
NATANY DAYANI DE SOUZA ASSAI ${ }^{*}$ \\ ORCID: https://orcid.org/0000-0002-0851-9187 \\ FABIELE CRISTIANE DIAS BROIETTI ${ }^{\text {** }}$ \\ ORCID: https://orcid.org/0000-0002-0638-3036 \\ SERGIO DE MELLO ARRUDA ${ }^{1 * * *}$ \\ ORCID: https://orcid.org/0000-0002-4149-2182
}

RESUMO: Nesse artigo, nossa proposta centra-se em apresentar os resultados de um mapeamento realizado em periódicos da área de Ensino de Ciências acerca da temática estágio supervisionado na formação inicial de professores. Realizamos uma pesquisa denominada estado da arte em 56 periódicos, resultando em um total de 87 artigos analisados, os quais foram submetidos aos procedimentos da Análise de Conteúdo. Como resultados, encontramos 8 categorias que representam os principais aspectos abordados por pesquisadores/educadores acerca dos estágios supervisionados, a saber: estratégias didáticas; discussões teóricas sobre o campo de estágio supervisionado; instrumentos formativos; ação docente; concepções dos estagiários; aprendizagem docente; evidências da constituição da identidade docente e a relação entre os sujeitos envolvidos na tríade formativa. Destacamos que esta investigação nos permitiu visualizar uma discussão plural acerca dos Estágios Supervisionados nos cursos de licenciatura, suscitando reflexões acerca das tendências nesta área e lacunas ainda a serem investigadas colocando em evidência a formação docente.

Palavras chave: Estágio supervisionado. Estado da arte. Formação inicial de professores. Ensino de Ciências.

\footnotetext{
'Universidade Estadual de Londrina, Londrina, PR. Brasil.

“Doutoranda do Programa de Pós-graduação em Ensino de Ciências e Educação Matemática da Universidade Estadual de Londrina .Email:< natanyassai@gmail.com>.

"* Docente Adjunta do Departamento de Química da Universidade Estadual de Londrina. Email:<fabieledias@uel.br>.

"** Docente sênior da Universidade Estadual de Londrina e Professor Visitante Sênior da Universidade Tecnológica Federal do Paraná (UTFPR) - Londrina. Email:< sergioarruda@sercomtel.com.br > .
} 


\section{SUPERVISED INTERNSHIP IN TEACHER TRAINING: STATE OF THE ART OF NATIONAL RESEARCH IN SCIENCE TEACHING}

ABSTRACT: In this article, our proposal focuses on presenting the results of a mapping carried out in publications in the area of Science Teaching, focused on the topic supervised training in the initial formation of teachers. We carried out a study called state of the art in 56 periodic publications, resulting in a total of 87 articles analyzed, which were submitted to Content Analysis procedures. As results, we found 8 categories that represent the main aspects addressed by researchers/educators about the supervised stages, namely: didactic strategies; theoretical discussions about supervised internship; training tools; teaching action; trainee conceptions; teacher learning; evidences of the constitution of the teaching identity and the relation between the subjects involved in the formative triad. We emphasize that this research allowed us to visualize a plural discussion about Supervised training in undergraduate courses, provoking reflections about the trends in this area and gaps still to be investigated, highlighting teacher education.

Keywords: Supervised training. State of the art. Initial teacher education. Science Teaching.

\section{INTRODUÇ̃̃O}

O estágio supervisionado é, frequentemente, parte integrante dos cursos de nível superior, tendo como um de seus objetivos estabelecer o primeiro contato de muitos estudantes com o mercado de trabalho. O estágio faz parte da formação do aluno e do projeto pedagógico de determinados cursos, inclusive nos específicos de formação de professores. Buriolla (1995) argumenta que o estágio é essencial à formação do aluno, enquanto parte integrante dos processos de ensino e aprendizagem permitindo uma reflexão sobre a ação profissional; uma visão crítica da dinâmica das relações existentes no campo institucional e para possibilitar a elaboração de novos conhecimentos.

No Brasil, a preocupação com a formação de professores resultou na efetivação de políticas voltadas para os cursos de formação inicial após a Lei n. 9.294/96 - Lei de Diretrizes e Bases (BRASIL, 1996). Desde então, o Brasil tem adotado políticas específicas para a formação dos professores (BRASIL, 2002; 2009a, 2009b, 2015).

Estes documentos apontam diretrizes para a Política Nacional de Formação de Professores e estabelecem princípios, dinâmicas formativas e procedimentos a serem observados nos programas e cursos de formação. Trata-se de um conjunto de procedimentos 
a serem observados na organização institucional e curricular dos estabelecimentos de ensino superior.

Nesse contexto, as Diretrizes Curriculares Nacionais para formação de professores emergem com a perspectiva de mudança de concepção educacional, pressupondo uma reformulação para os cursos de licenciatura plena e regulamentação para os estágios. Um trecho do parecer CNE/CP 09/2001 ilustra tais mudanças (BRASIL, 2002a, p. 4), ao considerar que um dos principais problemas da formação docente resulta do " [...] preparo inadequado dos professores cuja formação se manteve, predominantemente, em um formato tradicional, que não contempla muitas das características consideradas na atualidade". Dentre as características citadas no documento, refere-se ao papel atribuído ao estágio supervisionado durante a formação inicial e a sua desarticulação com as demais disciplinas que compõem o corpo de conhecimentos específicos.

Pimenta e Lima (2012) destacam o estágio, componente curricular obrigatório dos cursos de formação de professores, como eixo central desses cursos, pois apresenta características indispensáveis à construção do profissional docente, no que se refere à atribuição de sentido da profissão; aquisição de competências e habilidades, e emancipação profissional e construção da identidade profissional.

O espaço destinado ao estágio supervisionado oportuniza ao licenciando o contato com o seu futuro campo de trabalho, embora, por muito tempo, tenha sido considerado um mero campo de aplicação das teorias, estabelecendo uma dicotomia nos cursos de formação inicial de professores.

Fiorentini e Castro (2003), ressaltam que a prática de ensino e o estágio supervisionado podem ser caracterizados como um momento especial do processo de formação do professor em que ocorre, de maneira mais efetiva, a transição ou a passagem de aluno a professor. Essa inversão de papéis não é tranquila, pois envolve a construção e a desconstrução de expectativas; anseios; tensões e conflitos entre o que se sabe ou idealiza e aquilo que efetivamente pode ser realizado na prática.

Considerando o estágio supervisionado como um dos pilares da formação inicial e da construção da identidade docente, nossa proposta neste artigo consiste em apresentar os resultados de um mapeamento realizado em periódicos da área de Ensino de Ciências, em busca de aspectos apontados nos artigos a respeito da organização curricular e o desenvolvimento dos estágios supervisionados nos cursos de formação inicial de professores. 


\section{ENCAMINHAMENTO METODOLÓGICO}

Diante do objetivo pretendido - apresentar os resultados de um mapeamento realizado em periódicos da área de Ensino de Ciências acerca da temática estágio supervisionado na formação inicial de professores - realizamos uma pesquisa denominada como "estado da arte" ou "estado do conhecimento". De acordo com Ferreira (2002), este tipo de pesquisa apresenta caráter inventariante e descritivo, e busca identificar os aspectos e dimensões que vêm sendo destacados nas produções acadêmicas (dissertações de mestrado, teses de doutorado, produções em periódicos, anais de eventos científicos) em diferentes épocas e lugares, destacando formas e em que condições têm sido produzidas à luz de categorias, de maneira individual e no conjunto.

Para este artigo, o mapeamento das produções científicas sobre os estágios supervisionados na formação inicial de professores da área de Ensino de Ciências pautou-se no instrumento proposto por Assai, Arrigo e Broietti (2018), o qual apresenta uma lista representativa de 56 periódicos concernentes à referida área para consulta em trabalhos de levantamentos bibliográficos. Tal lista compõe periódicos nacionais com Qualis A1, A2 e B1 (os maiores estratos), selecionados em um movimento minucioso de utilização de alguns filtros de busca (Ciência, Ensino, Química e Educação) associados ao Ensino de Ciências.

Dos 56 periódicos constituintes da lista, 2 (Ciência em Tela e Revista Brasileira de História da Ciência) não apresentam sistema de busca em seus sites, o que se faria necessário acessar edição por edição da revista, logo, foram excluídos do acervo. Para os demais periódicos, com o intuito de realizar o levantamento dos artigos utilizamos a ferramenta "Pesquisar", e o campo de busca denominado "pesquisar termo em todas as categorias", inserindo as palavras-chave "estágio" e "estágio supervisionado". A busca nas páginas dos 54 periódicos resultou em um acervo que totalizou 495 artigos.

Entretanto, para averiguar se os artigos selecionados estavam em consonância com o objetivo dessa pesquisa, foi necessário acessar cada artigo localizado na página de cada periódico, verificando se estes possuíam como foco de pesquisa o estágio supervisionado nos cursos de formação inicial de professores da área de Ensino de Ciências. ${ }^{1}$

Os artigos que não atendiam a essa solicitação foram excluídos do acervo. Os critérios utilizados para a exclusão dos artigos estão listados a seguir:

a) quando o termo estágio não se referia ao estágio supervisionado como parte curricular integrante dos cursos de licenciatura, como, por 
exemplo, no artigo de Santos (2005) da revista ACTA SCIENTIAE: Revista de Ensino de Ciências e Matemática, que tratam os estágios de desenvolvimento de Piaget para a elaboração de conceitos de Física;

b) quando se tratava de uma pesquisa envolvendo estágio na formação inicial de professores de outras áreas que não das licenciaturas da área de Ensino de Ciências, como Pedagogia (PASSOS, 2013), História (SILVA JÚNIOR, 2015), Inglês (DIAS, MASCARENHAS FILHO e ANDRADE, 2017), entre outros;

c) quando faziam referência ao estágio de docência da PósGraduação, por exemplo, Almeida e Terán (2013) apresentam a experiência de estágio em docência na Pós-Graduação em Educação e Ensino de Ciências, realizada na Universidade do Estado do Amazonas e analisa a avaliação feita pelos estudantes acerca desta disciplina;

d) quando discutiam sobre o Programa de Bolsa de Iniciação à Docência (PIBID); conhecimentos profissionais e/ou disciplinas constituintes da grade curricular das licenciaturas, fazendo referência ao estágio supervisionado ao tecer suas considerações, no entanto, não possuíam como objetivo central analisar/discutir as implicações do estágio supervisionado na formação inicial. Um exemplo é o caso da pesquisa de Martins e Slavez (2015) que compara o PIBID e o Programa de Residência Pedagógica (PRP), oferecido pela Universidade Federal de São Paulo (Unifesp), como políticas públicas de iniciação à docência.

Esse movimento de exclusão deu origem ao corpus dessa investigação, constituída por 87 artigos, que representam 17,5\% do acervo inicial disponível nas páginas dos periódicos (495 artigos). Deste total, 49 artigos foram selecionados a partir do filtro Ciência, 13 artigos são provenientes do filtro Ensino, 8 artigos selecionados pelo filtro Química e, por fim, 17 artigos pelo filtro Educação. A lista com a relação completa dos artigos constituintes do corpus encontra-se em apêndice.

$\mathrm{Na}$ tentativa de compreender aspectos pautados e discutidos por pesquisadores/educadores acerca dos estágios supervisionados, utilizamos os procedimentos da Análise de Conteúdo proposto por Bardin (2011). Segundo a autora, as etapas da análise são i) préanálise, ii) exploração do material e iii) tratamento dos resultados. A pré-análise contempla a organização do material, a qual consideramos todo o movimento de seleção do corpus acima descrito, assim como a codificação dos 87 artigos que o compõem. A codificação e a identificação para cada artigo está de acordo com o nome da revista, ano de publicação e a ordem crescente de relação na página do periódico, por exemplo, ACTA2013_1; AMAZÔNIA2017_5; etc.

A exploração do material compreende um estudo aprofundado do corpus. Mediante uma primeira leitura elaboramos um documento 
no excel $[$ compilando um fichamento com as informações principais sobre os artigos: título, codificação, ano de publicação, área, autores/ filiação, objetivo, sujeitos de pesquisa, metodologia, resultados e referências citadas. Posteriormente, retomamos ao objetivo de cada trabalho e realizamos uma interpretação das discussões envolvidas em cada uma das produções para averiguar se os objetivos haviam sido contemplados, de forma a agrupá-los conforme características comuns, resultando no processo de categorização. Esse processo resultou em 8 categorias emergentes, codificadas como C1, C2...C8, descritas e exploradas na próxima seção.

O tratamento dos resultados compreende a interpretação das categorias, pautados em inferências embasadas no referencial teórico adotado, análise crítica e também a intuição do pesquisador.

\section{PARA ALÉM DO CORPUS: UM PANORAMA DAS PESQUISAS NACIONAIS}

Diante dos 87 artigos selecionados para análise, estes publicados até o mês de abril de 2018 (período final estabelecido para o levantamento), destacamos algumas considerações iniciais. Os artigos selecionados estão distribuídos em 34 periódicos distintos perfazendo um intervalo de 18 anos (2000 a 2018). A Figura 1 mostra a disseminação das produções anualmente, com uma quantidade ínfima de produções no período de 2000-2007, totalizando apenas 5 artigos publicados, um crescimento entre os anos 2008 e 2010; uma redução em 2011 e uma nova ascensão após 2013.

FIGURA 1. Quantidade de artigos publicados com a temática estágio supervisionado anualmente no período de 2001-2018

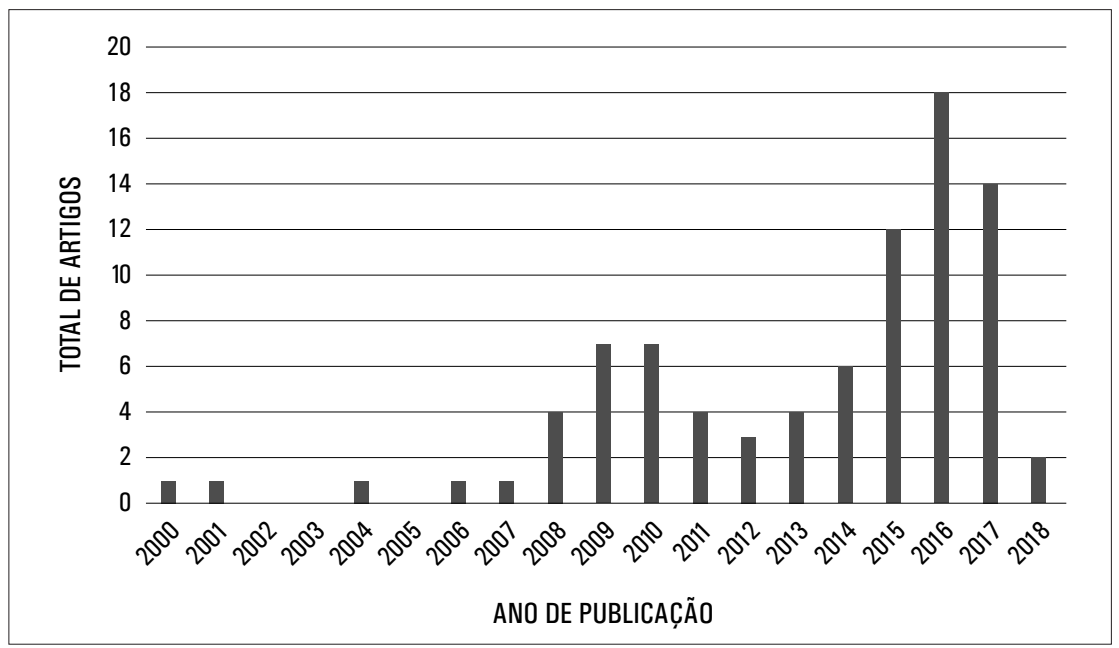

Fonte: elaboração própria. 
Perante o exposto na Figura 1, é possível constatar que a temática do estágio supervisionado se desenvolveu como campo de pesquisa na última década (2008-2018), fato que pode ser explicado em decorrência das resoluções instituídas pelo Conselho Nacional de Educação (CNE), como as Diretrizes Nacionais Curriculares para a Formação de Professores (CNE/CP 09/2001), que norteou mudanças nos cursos de licenciatura, incluindo o estágio supervisionado e delimitou a década de implantação (2001-2010) como prazo de tais mudanças.

Tais alterações permitiram modificações nos cursos de licenciatura e na organização dos estágios, resultando em incentivo para pesquisas acerca desse componente obrigatório dos cursos de formação inicial de professores. De maneira análoga, mais da metade dos artigos pertencentes ao corpus, 46 artigos, foram publicados após o ano de 2015, ano em que novamente ocorrem alterações nas políticas públicas dos cursos de licenciatura por meio da resolução CNE/CP 02/2015 (BRASIL, 2015). Apesar do documento não alterar as disposições ou legislação a respeito do estágio supervisionado, altera a organização da estrutura curricular dos cursos de licenciatura, impulsionando novamente que as pesquisas se voltem para temáticas que circundam os componentes relacionados à formação inicial de professores.

No que tange à distribuição dos artigos por cursos específicos, relacionados à área de Ensino de Ciências, encontramos 30 artigos que versam sobre a disciplina de estágio supervisionado no curso de Ciências Biológicas. Os cursos de formação inicial de professores de Física e Química abrangem uma quantidade de pesquisas semelhantes, 20 e 18, respectivamente. Encontramos também alguns artigos (5) que discutem sobre o estágio supervisionado nos cursos de Licenciatura em Ciências da Natureza, que possuem como foco formar professores com uma visão abrangente dessas ciências (Astronomia, Geociências, Biologia, Física e Química). A distribuição por curso pode ser visualizada na Figura 2. 
FIGURA 2. Distribuição percentual por área

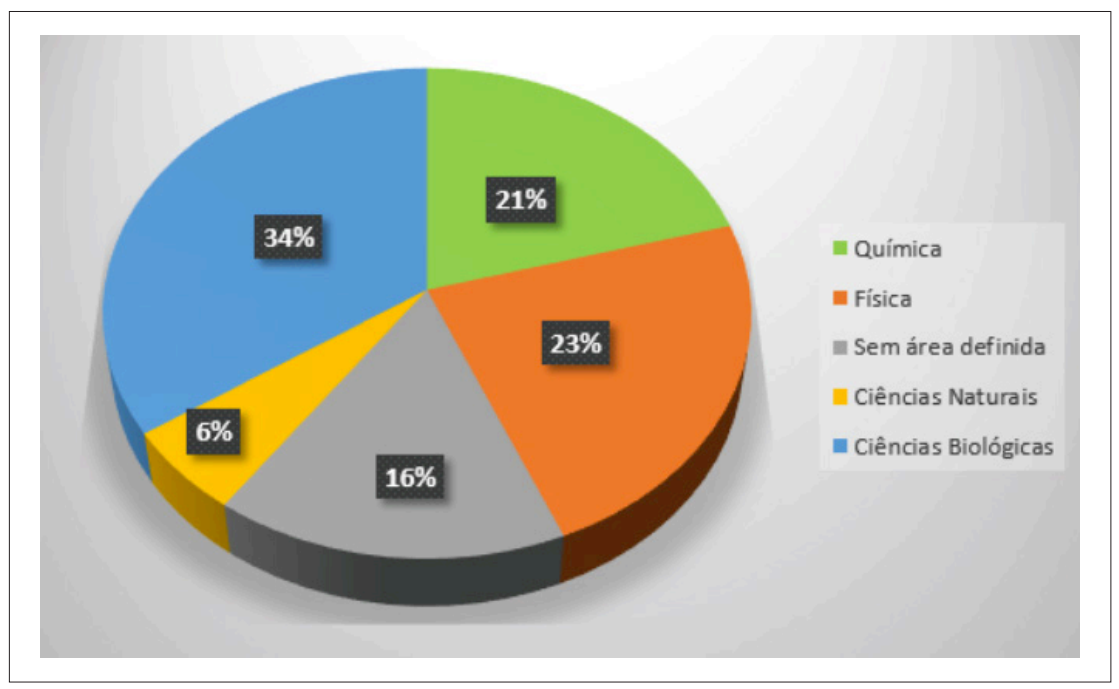

Fonte: elaboração própria.

Encontramos também uma quantidade considerável de artigos que versam sobre o estágio supervisionado de forma interdisciplinar, sem uma área definida com o predomínio de discussões teóricas a respeito da temática em questão, provenientes majoritariamente dos periódicos pertencentes ao filtro "Educação".

Retomando o objetivo central deste artigo, que busca compreender aspectos que estão sendo pautados e discutidos, por pesquisadores/educadores acerca dos estágios supervisionados, os artigos selecionados foram analisados e posteriormente categorizados mediante a leitura e interpretação dos objetivos e discussões envolvidas em cada uma das produções. O Quadro 1 apresenta o resultado do processo de categorização, a descrição das categorias e o total de artigos por categoria. Na descrição destacamos os núcleos de sentido ${ }^{2}$ que permearam o agrupamento dos dados em cada categoria. 
QUADRO 1. Categorias emergentes, descrições e a quantidade total de artigos por categoria

\begin{tabular}{|c|c|c|c|}
\hline CATEGORIA & DESCRIC̣ÃO & ARTIGOS & TOTAL \\
\hline $\begin{array}{l}\text { C1 } \\
\text { Estratégias } \\
\text { didáticas }\end{array}$ & $\begin{array}{l}\text { Essa categoria compreende } \\
\text { os artigos que apresentam } \\
\text { propostas de estratégias } \\
\text { de ensino e aprendizagem } \\
\text { desenvolvidas pelos estudantes } \\
\text { na disciplina de estágio } \\
\text { supervisionado. } \\
\text { Núcleos de sentido: estratégia } \\
\text { formativa; estratégias didáticas; } \\
\text { potencialidades didáticas. }\end{array}$ & $\begin{array}{l}\text { AMAZÔNIA2016_2; } \\
\text { EENCI2017_2 } \\
\text { AMAZÔNIA2015_4; } \\
\text { ARETÉ2008_3; } \\
\text { ARETÉ2016_4; } \\
\text { EENCI2017_5; } \\
\text { CAD_BRAS_ENS_FÍSICA2016_1 } \\
\text { CIEDU2017_6; } \\
\text { IENCI2011_2; } \\
\text { CIENCIA_E_ENS2014_1; } \\
\text { ONESC2014_7; } \\
\text { UNOPAR2014_1; } \\
\text { DEBATES2015_1; } \\
\text { EENCI2006_3; } \\
\text { EENCI2009_6; } \\
\text { ENCITEC2011_2; } \\
\text { ENSAIO2009_1; } \\
\text { ENSAIO2015_3; } \\
\text { ENSAIO2017_5; } \\
\text { AMAZÔNIA2017_5 } \\
\text { REV_DOC_ES2016_3; } \\
\text { ENSINO_E_PESOUISA2017_1; } \\
\text { ONESC2008_8; RBECT2016_1; } \\
\text { REV_BRA_ENS_FÍSICA2017_1. }\end{array}$ & 25 \\
\hline $\begin{array}{l}\text { C2 } \\
\text { Legislação } \\
\text { e currículo }\end{array}$ & $\begin{array}{l}\text { Artigos que dissertam sobre } \\
\text { legislação, currículo e demais } \\
\text { documentos norteadores do } \\
\text { componente curricular estágio } \\
\text { supervisionado, nos cursos } \\
\text { de licenciatura. } \\
\text { Núcleos de sentido: legislação; } \\
\text { avaliação da disciplina de } \\
\text { prática de ensino e estágio; } \\
\text { reflexão sobre a estruturação } \\
\text { dos estágios; reformulação } \\
\text { curricular; política curricular; } \\
\text { construções teóricas. }\end{array}$ & $\begin{array}{l}\text { ARETÉ2009_2; } \\
\text { ARETÉ2009_5; } \\
\text { ATOS_DE_PESQUISA2011_1; } \\
\text { CADERNOS_DE_EDU2013_2; } \\
\text { CADERNOS_PES_EDU2010_1; } \\
\text { CIEDU2001_1; } \\
\text { CIEDU2014_7; } \\
\text { DEBATES2016_2; } \\
\text { EDU_EM_REV2018_1; } \\
\text { EENCI2010_1; } \\
\text { ENSINO_EM_REVISTA2017_2; } \\
\text { ONESC2008_5; } \\
\text { ONESC2016_6; } \\
\text { REV_BRA_ENS_FÍSICA2017_2; } \\
\text { REV_BRA_EDU2013_1; } \\
\text { REV_EDU_PUC_CAM2009_1; } \\
\text { REV_IBER02017_1; } \\
\text { REVEDUC2014_1; } \\
\text { TEAR2015_1. }\end{array}$ & 20 \\
\hline
\end{tabular}




\begin{tabular}{|c|c|c|c|}
\hline $\begin{array}{l}\text { C3 } \\
\text { Instrumentos } \\
\text { formativos }\end{array}$ & $\begin{array}{l}\text { Pesquisas que analisam o } \\
\text { emprego de instrumentos } \\
\text { formativos para a } \\
\text { aprendizagem docente. } \\
\text { Núcleos de sentido: instrumentos } \\
\text { de registro; instrumentos } \\
\text { formativos; práticas de escrita. }\end{array}$ & $\begin{array}{l}\text { AMAZÔNIA2012_1; } \\
\text { AMAZÔNIA2016_3; } \\
\text { IENCI2017_4; } \\
\text { CIEDU2010_5; } \\
\text { ENSAIO2016_4; } \\
\text { ONESC2013_1; } \\
\text { ONESC2010_2; } \\
\text { ONESC2008_3; } \\
\text { RBECT2015_2; } \\
\text { REV_DOC_ES_2; } \\
\text { REV_TEM_ESPA2015_2. }\end{array}$ & 11 \\
\hline $\begin{array}{l}\text { C4 } \\
\text { Ação } \\
\text { docente }\end{array}$ & $\begin{array}{l}\text { Artigos que objetivam investigar } \\
\text { a ação pedagógica, ou seja, } \\
\text { como os estagiários agem } \\
\text { durante o período de } \\
\text { regências de classe. } \\
\text { Núcleos de sentido: análise da } \\
\text { ação docente; experiência de } \\
\text { estagiários; prática pedagógica; } \\
\text { prática docente; ações } \\
\text { pedagógicas; inserção } \\
\text { na docência. }\end{array}$ & $\begin{array}{l}\text { CIEDU2016_3; } \\
\text { CRIAR2015_1; } \\
\text { EDU_REALIDADE2016_1; } \\
\text { EENCI2017_2; } \\
\text { ENSAIO2007_2; } \\
\text { ENSINO_E_PESQUISA2016_3; } \\
\text { IENCI2011_2; } \\
\text { RBPEC2011_3; } \\
\text { REV_ELET_EN_SAÚDE_ } \\
\text { AMB2017_1. }\end{array}$ & 9 \\
\hline $\begin{array}{l}\text { C5 } \\
\text { Concepções } \\
\text { dos } \\
\text { estagiários }\end{array}$ & $\begin{array}{l}\text { Pesquisas que dissertam sobre } \\
\text { as concepções evidenciadas por } \\
\text { licenciandos durante a realização } \\
\text { do estágio supervisionado acerca } \\
\text { de diversos temas relacionados } \\
\text { à formação docente, tais como } \\
\text { experimentação, prática docente, } \\
\text { estágio supervisionado, } \\
\text { oficinas pedagógicas. } \\
\text { Núcleos de sentido: } \\
\text { representações; expectativas e } \\
\text { receios; opiniões; percepções; } \\
\text { anseios; dúvidas; expectativas } \\
\text { e concepções. }\end{array}$ & $\begin{array}{l}\text { ACTA2008_2; } \\
\text { AMAZÔNIA2016_3; } \\
\text { CIEDU2012_2; } \\
\text { CIEDU2017_6; } \\
\text { REV_TEM_ESPA2015_1; } \\
\text { RBECT2015_3; } \\
\text { ENCITEC_1; } \\
\text { RBPEC2004_4; } \\
\text { EENCI2016_4. }\end{array}$ & 9 \\
\hline
\end{tabular}




\begin{tabular}{|c|c|c|c|}
\hline $\begin{array}{l}\text { C6 } \\
\text { Aprendizagem } \\
\text { docente }\end{array}$ & $\begin{array}{l}\text { Artigos que versam sobre a } \\
\text { aprendizagem das competências, } \\
\text { habilidade, saberes, } \\
\text { conhecimentos necessários para } \\
\text { a formação do futuro professor. } \\
\text { Núcleos de sentido: saberes } \\
\text { construídos durante o } \\
\text { período de estágio; saberes, } \\
\text { conhecimentos e ambientes de } \\
\text { aprendizagem; aprendizagens } \\
\text { desenvolvidas durante o estágio; } \\
\text { apropriação e mobilização de } \\
\text { saberes; processos de criação e } \\
\text { interações didáticas; processos } \\
\text { de formação para a docência. }\end{array}$ & $\begin{array}{l}\text { CIEDU2010_4; } \\
\text { CIEDU2015_8; } \\
\text { RENCIMA2016_1; } \\
\text { CAD_BRAS_ENS_- } \\
\text { FÍSICA2016_2; } \\
\text { ENSIN0_E_PESQUISA2017_2; } \\
\text { RBPEC2016_1; } \\
\text { RBPEC2017_2; } \\
\text { REV_DOC_ES2016_1. }\end{array}$ & 8 \\
\hline $\begin{array}{l}\text { C7 } \\
\text { Identidade } \\
\text { docente }\end{array}$ & $\begin{array}{l}\text { Essa categoria engloba os } \\
\text { trabalhos que possibilitam } \\
\text { discutir evidências de } \\
\text { constituição da identidade } \\
\text { docente por parte dos } \\
\text { estagiários, utilizando-se do } \\
\text { discurso, dos registros e da } \\
\text { memória, no qual transitam da } \\
\text { posição de se ver apenas como } \\
\text { aluno a seu ver-se } \\
\text { como professor. } \\
\text { Núcleos de sentido: construção } \\
\text { de identidade docente; } \\
\text { autoria; relações de poder } \\
\text { e alteridade; constituição } \\
\text { profissional; autonomia } \\
\text { profissional/intelectual; indícios } \\
\text { de construção da autonomia } \\
\text { docente; constituir-se professor. }\end{array}$ & $\begin{array}{l}\text { ACTA2013_1; } \\
\text { ARETÉ2009_1; } \\
\text { IENCI2016_1; } \\
\text { IENCI2011_5; } \\
\text { INT_DA_EDU2015_1; } \\
\text { ONESC2018_4; } \\
\text { REV_BRA_EDU2008_2. }\end{array}$ & 7 \\
\hline $\begin{array}{l}\text { C8 } \\
\text { Tríade } \\
\text { formativa }\end{array}$ & $\begin{array}{l}\text { Referem-se a pesquisas } \\
\text { que possuem como objetivo } \\
\text { relacionar pelo menos dois } \\
\text { sujeitos envolvidos na tríade } \\
\text { formativa - professor formador/ } \\
\text { estagiário/supervisor do estágio. } \\
\text { Núcleos de sentido: constituição } \\
\text { de um grupo docente; análise } \\
\text { das ações do supervisor pelo } \\
\text { estagiário; relação entre } \\
\text { formador x estagiário. }\end{array}$ & $\begin{array}{l}\text { CADERNOS_DE_EDU2013_2; } \\
\text { ENSINO_EM_REVISTA2015_1; } \\
\text { IENCI2010_3. }\end{array}$ & 3 \\
\hline
\end{tabular}

Fonte: elaboração própria. 
Na sequência discutiremos cada uma das categorias, apresentando fragmentos representativos dos artigos.

A categoria C1 - estratégias didáticas - englobou a maior quantidade de artigos, e todos apresentam propostas de estratégias de ensino e aprendizagem desenvolvidas pelos estudantes na disciplina de estágio supervisionado. Apropriamo-nos do conceito de estratégia proposto por Masetto (2003) como um meio utilizado pelo professor para facilitar o processo de aprendizagem dos alunos. Encontramos uma variedade de propostas desenvolvidas pelos licenciandos ao longo do estágio supervisionado, tais como: utilização de metáforas; ações interdisciplinares; abordagens incluindo a História e Filosofia da Ciência; Ciclo da Experiência Kellyana (CEK) atrelado ao método da aprendizagem cooperativa; uso de textos de divulgação científica; inclusão de estágio em gestão educacional; abordagem temática no enfoque Ciência-Tecnologia-Sociedade (CTS); metodologia por projetos; práticas inclusivas; utilização de blogs, além de uma diversidade de modalidades de experimentação: tradicional; experimentação investigativa; experimentação móvel e experimentação virtual. Deparamo-nos ainda com artigos que defendem a utilização de uma combinação variada de recursos didáticos distintos, denominado como pluralismo metodológico (LABURÚ, ARRUDA, NARDI, 2003). Na continuidade apresentamos alguns trechos de artigos representativos desta categoria.

Trata-se de um estudo que analisa as perspectivas da metodologia de projetos na formação de professores reflexivos e pesquisadores, entendendo tal prática como uma estratégia formativa que apoia de um lado a formação docente e de outro contribui com os contextos locais em que se insere (EENCI2006_3).

Na tentativa de superação da fragmentação, observamos como possibilidades a utilização de estratégias ante ao programa tradicional, a inclusão da História e Filosofia da Biologia (HFB) e a inserção de aulas práticas participativas (AMAZÔNIA2015_4).

$\mathrm{Na}$ categoria C2 - Legislação e currículo - classificamos pesquisas sobre legislação, currículo e documentos norteadores dos estágios supervisionados nos cursos de licenciatura. Essa categoria também englobou uma quantidade expressiva de trabalhos (20 artigos) que discutem a legislação à luz de referenciais teóricos em torno do eixo articulador da disciplina de estágio ou apresentam relatos de experiência que descrevem e/ou avaliam a estruturação do estágio supervisionado em algumas instituições públicas de Ensino Superior (UEL, UNESP, UNB, UFAL). Seguem fragmentos de alguns artigos selecionados para esta categoria. 
Este artigo tem como objetivo apresentar e discutir os Estágios desenvolvidos no curso de Licenciatura em Química da UEL. [...] o curso de Licenciatura em Química da UEL tem procurado atender a essas necessidades, a partir das modificações já realizadas na estrutura dos componentes curriculares distribuídos ao longo do curso e das inovações implementadas nos Estágios (QNESC2016_6).

$\mathrm{O}$ artigo analisa o impacto das novas legislações educacionais brasileiras na formação de professores. [...] fazendo uma proposta para a distribuição dos conteúdos específicos nos currículos dos cursos de licenciatura (CIEDU2001_1).

A categoria C3, denominada como Instrumentos formativos, contou com 11 artigos que descrevem recursos de coletas de dados, que configuram o estado de aprendizagem dos educandos (LUCKESI, 2000). Essa categoria englobou os artigos que analisam o emprego de instrumentos formativos para a aprendizagem docente. Tais instrumentos foram utilizados para analisar o processo formativo durante o período de estágio supervisionado, seja pela análise dos planejamentos de aula; questões conceituais acerca de um determinado tema; narrativas; diários de aula ou a utilização combinada do microensino com a autoscopia para avaliar o desenvolvimento da formação dos licenciandos. A seguir apresentamos exemplos de artigos classificados nesta categoria.

Apresentamos nesta pesquisa uma proposta que foi desenvolvida com os estudantes da disciplina de Estágio Supervisionado em Química da UFJF no ano de 2013, buscando (re)pensar as práticas de escrita para além dos relatórios técnicos que comumente são desenvolvidos neste momento da formação inicial (ENSAIO2016_4).

A escrita de diários de campo foi empregada como instrumento formativo do processo de aprendizagem sobre a docência (QNESC2013_1).

Na categoria C4 - Ação Docente - identificamos 9 artigos que objetivavam investigar a ação pedagógica dos estagiários durante o período de regências de classe, no período do estágio supervisionado. Estes artigos buscavam compreender os aspectos envolvidos no desenvolvimento das regências; as condições de aprendizagem; habilidades de planejar e promover situações de ensino, realizando i) descrições da prática dos estagiários ou, ii) à luz de um instrumento próprio para a análise da ação docente (ARRUDA; LIMA; PASSOS, 2011). Ainda para essa categoria relacionada à ação docente, foi possível constatar maior quantidade de pesquisas acerca da ação dos licenciandos em Ciências Biológicas; seguido pelos licenciandos em Física e apenas um trabalho que analisa a ação do estagiário de Química. Seguem exemplos de artigos que se enquadram nesta categoria. 
Nesse trabalho analisamos uma prática pedagógica reflexiva desenvolvida num curso de formação inicial de professores de Ciências e suas contribuições para uma preconizada formação interdisciplinar (EENCI2006_2).

Esta pesquisa esteve ligada à disciplina de Estágio Supervisionado II [...] o problema central da pesquisa é: Como as ações pedagógicas de uma professora regente contribuíram para se aproximar ou distanciar da perspectiva da avaliação formativa? Quais foram as contribuições para reflexão da própria prática? (REV_ ELET_EN_SAÚDE_AMB2017_1).

A categoria C5 - Concepções dos estagiários - englobou pesquisas que investigam as concepções/ideias dos estagiários acerca de diversos temas relacionados à formação docente, ou seja, as teorias ou explicações elaboradas pelos estudantes para explicar determinado fenômeno. Tais concepções advêm de uma aprendizagem espontânea proveniente de diversas fontes e acompanham os estudantes também em sala de aula (CARRETERO, 1993). Para essa categoria foram agrupadas as pesquisas que dissertam sobre as concepções, opiniões, anseios evidenciados por licenciandos durante a realização do estágio supervisionado, tais como experimentação, prática docente, estágio supervisionado, oficinas pedagógicas. Apresentamos, na sequência, trechos representativos de alguns artigos classificados nesta categoria.

Como o principal objetivo deste trabalho é adentrar a realidade dos estagiários, compreender e explorar suas opiniões, percepções, anseios, dúvidas, expectativas e concepções a respeito da profissão docente e do cotidiano escolar, optou-se pelo estudo de cunho qualitativo, por ser de caráter observativo, descritivo e de compreensão da realidade (CIEDU2012_2).

O processo investigativo realizado dissertou concepções de licenciandos de um curso de Química quanto ao uso do laboratório no ensino de Química a partir de uma abordagem facilitadora, em particular a abordagem Predizer, Observar e Explicar (POE), onde foi possível verificar junto a estes uma possível evolução conceitual quanto aos objetivos de aulas experimentais (ACTA2008_2).

Para a categoria C6 - Aprendizagem docente - foram alocados 8 trabalhos que possuem como essência a apropriação e a mobilização de conhecimentos docentes, processos de criação e interações didáticas durante o período do estágio. A aprendizagem docente refere-se à aprendizagem das competências, habilidades, conhecimentos necessários para a formação do futuro professor. Esses saberes mobilizados e empregados na prática cotidiana servem para resolver os problemas dos professores em exercício e para dar sentido às situações de trabalho que lhes são próprias (TARDIF; RAYMOND, 2000). Abaixo elencamos exemplos de artigos que se enquadram nesta categoria.

Neste trabalho apresentamos os resultados de uma investigação a respeito da construção dos saberes docentes, durante a realização do estágio supervisionado 
da licenciatura de Física. [...]. Com base nessas representações, procuramos verificar quais saberes os estagiários conseguiram construir durante esse período e caracterizar a singularidade de sua ação docente. (CIEDU_4)

[...] como objetivo principal a identificação de saberes de argumentação docente que foram mobilizados ou desenvolvidos nos momentos reflexivos relacionados ao estágio supervisionado de uma disciplina de um curso de Licenciatura em Química de uma universidade pública brasileira. (RBPEC_1)

Encontramos, também, algumas produções (7 artigos) que possuem como foco a construção da Identidade docente dos estagiários, classificados na Categoria 7 - Identidade docente. Dubar (2009) define identidade como traços e características que tornam possível distinguir sujeitos individualmente e grupos, em determinados contextos e momentos sócio-históricos, de acordo com os significados que atribuem ao "ser professor". Portanto, nesta categoria estão incluídos artigos que discutem evidências de constituição da identidade docente por parte dos estagiários, utilizando-se do discurso, dos registros e da memória, no qual transitam da posição de se ver apenas como aluno a seu ver-se como professor. Na sequência apresentamos fragmentos dos artigos alocados nesta categoria.

Este trabalho analisa como o imaginário de um professor em formação inicial articula as relações de poder, a construção de identidade, o processo de autoria e as relações de alteridade.[...] Concluímos que a identidade docente, o processo de autoria e as relações de poder e de alteridade estabelecidas entre o licenciando e o outro são interdependentes, móveis e articuladas pelo licenciando dialeticamente nas mobilizações das imagens sobre o discurso escolar (IENCI_1).

[...] quais indícios de construção da autonomia docente podem-se atingir durante processos formativos reflexivos contemplados semestralmente nas disciplinas de Metodologia e Prática de Ensino de Física de um curso de Licenciatura em Física? (IENCI_5).

A categoria C8 - tríade formativa -, foi elaborada inspirada na tríade de interação profissional proposta por Zanon (2003), que argumenta a importância das interações de licenciandos, professores formadores e professores supervisores na elaboração conceitual da prática docente do futuro professor. Essa categoria englobou a menor quantidade de trabalhos (apenas 3), os quais possuem como objetivo relacionar pelo menos dois sujeitos envolvidos na tríade formativa (professor formador/estagiário/supervisor). Vale ressaltar que em nenhum dos trabalhos agrupados nessa categoria encontramos dados que analisam a interação entre os três sujeitos na formação do futuro professor no Brasil. O artigo de Gervais (2013) é o que mais se aproxima dessa proposta ao elaborar um quadro descritivo de orientações para professores formadores e supervisores na 
formação do estagiário com base na legislação e objetivos dos cursos de formação de professores em Quebec, Canadá. Abaixo elencamos exemplos de artigos representativos desta categoria.

Essa investigação caracteriza a aquisição/incorporação de esquemas de percepções, pensamentos e ações do professor supervisor pelo estagiário no decorrer de um projeto de estágio colaborativo em Física (ENSINO_EM_REVISTA2015_1).

Um quadro de referência propõe as orientações para a formação dos professores associados e dos supervisores universitários e as competências que cada um dos grupos de formadores deveria tentar desenvolver na formação dos estagiários (CADERNOS_DE_EDU2013_2).

Interpretaremos essas mudanças como o fruto do acoplamento entre as intervenções da professora da disciplina de Prática e as respostas dos alunos das licenciandas durante o Estágio. [...] tornar-se um grupo docente (IENCI2010_3).

Diante das informações apresentadas no Quadro 1, constatase que a quantidade total de artigos distribuídos nas oito categorias (92) é superior à quantidade de artigos constituintes do corpus (87). Isso ocorreu, pois, apesar do esforço para distribuir cada artigo em apenas uma categoria, alguns deles apresentam explicitamente mais de um objetivo ou durante as discussões tecem considerações sobre mais de uma temática, o que nos levou a alocar 5 artigos de forma não excludente. A pesquisa de Silva e Bastos (2017), por exemplo, apresenta dois objetivos distintos:

[...] apresentar uma proposta de estágio supervisionado para licenciandos em Física na modalidade EAD utilizando os pressupostos do Ciclo da Experiência Kellyana (CEK), atrelado ao método da aprendizagem cooperativa; e analisar as concepções dos sujeitos envolvidos na disciplina de estágio supervisionado acerca de aspectos que favorecem e/ou dificultam a atuação do estagiário no contexto escolar, e o outro, por licenciandos de Física, em relação à escolha da profissão "professor de Física" e aos aspectos que consideram mais relevantes na prática docente no Ensino Médio (CIEDU2017_6).

Portanto, cada objetivo se refere a uma categoria distinta, o primeiro objetivo foi classificado na C1 - Estratégias didáticas -, pela proposição de uma abordagem de aprendizagem cooperativa na Licenciatura em Física na modalidade à distância e, o segundo na C5 - Concepções dos estagiários -, por se tratar de uma análise das concepções sobre o estágio e a escolha pela docência.

O artigo de Shaw e Rocha (2017) tece suas considerações a respeito das atividades formativas de duas licenciandas em Ciências da Natureza sob duas vertentes:

Nesse trabalho analisamos uma prática pedagógica reflexiva desenvolvida num curso de formação inicial de professores de Ciências e suas contribuições para uma preconizada formação interdisciplinar (EENCI2017_2) 
A análise da experiência das licenciandas voltada ao desenvolvimento de uma sequência didática interdisciplinar na escola campo de estágio foi alocada na Categoria C4 - Ação docente. Além disso, a proposta de utilizar-se de um estágio interdisciplinar devido às características do curso de Ciências da Natureza, foi alocada também na Categoria 1 - Estratégias didáticas -, uma vez que envolveu uma série de atividades que vão além da ação das licenciandas na sala de aula, ocupando um espaço de discussão separada no artigo, no que tange à implantação da proposta na disciplina.

O artigo de Castro e Goldschmidt (2016) discute seus dados em função de duas vertentes: o que os estudantes acreditam ser a atividade experimental e, em um segundo momento, a reflexão sobre sua utilização na análise dos planejamentos de aula.

[...] o presente artigo tem o intuito de investigar as representações que os docentes em formação em Biologia possuem sobre as aulas práticas e como estas se fazem presentes quando estes têm a possibilidade de planejarem suas ações em sala de aula, no momento do estágio (AMAZÔNIA2016_3).

Dessa maneira o objetivo de investigação das concepções sobre aulas práticas compreende a Categoria C5 - Concepções dos estagiários-, e a utilização dos planejamentos de aula como instrumento formativo para a reflexão sobre o tema foi alocada na Categoria C2 - Instrumentos formativos.

A produção de Oliveira e Faria (2011) descreve de forma crítica e analítica todas as etapas do estágio, em especial são analisadas as aulas desenvolvidas sobre os temas: reprodução e sexualidade (IENCI2011_2). Ao lermos o objetivo do artigo é clara a intenção dos autores em analisar o conjunto de aulas ministradas pelas estagiárias, incidindo em uma seção de discussões destinadas a esse tópico, objetivo classificado na Categoria C4 - Ação docente. Entretanto, há uma outra seção no artigo que expõe e analisa as diversas estratégias metodológicas utilizadas pelas duplas e defendem uma postura pluralista para a formação do futuro professor, trecho categorizado como Estratégias didáticas (C1).

O artigo descreve de forma crítica e analítica todas as etapas do estágio, em especial são analisadas as aulas desenvolvidas sob os temas: reprodução e sexualidade. [...] Ao fim da pesquisa pode-se perceber que o uso de recursos didáticos alternativos foi positivo e chamou a atenção dos estudantes, estes afirmaram gostar da dinâmica adotada. (IENCI2011_2)

Por fim, Gervais (2013) realiza um movimento teórico de descrição dos cursos de formação de professores do Quebec (América do Norte), apresentando regulamentações, objetivos e 
reflexões sobre o estágio supervisionado, justificando a escolha pela Categoria C2 - legislação e currículo.

Este texto descreve a formação para o ensino no Quebec, que se apoia em um referencial de competências profissionais e que deixa bastante espaço para as experiências de estágio. Elementos da organização dos estágios são apresentados, destacando-se tendências a respeito da contribuição dos formadores e do desenvolvimento profissional dos estagiários, baseando-se em resultados de estudos (CADERNOS_DE_EDU2013_2).

Ao longo das discussões sobre a organização dos estágios o autor discorre sobre a importância dos estudantes, professores formadores e professores supervisores na disciplina, incluindo uma seção destinada à articulação e ao trabalho de supervisão pedagógica dos formadores de estagiários. Nessa seção foi elaborado um quadro de referência contendo orientações e competências para a formação dos professores associados e dos supervisores universitários para a formação dos estagiários, o que nos levou a alocar o artigo também na categoria C8 - tríade formativa.

A Figura 3 permite uma melhor visualização do processo de categorização apresentado no Quadro 1, quanto à distribuição percentual das pesquisas sobre estágio supervisionado por categoria.

FIGURA 3. Distribuição percentual dos artigos por categoria

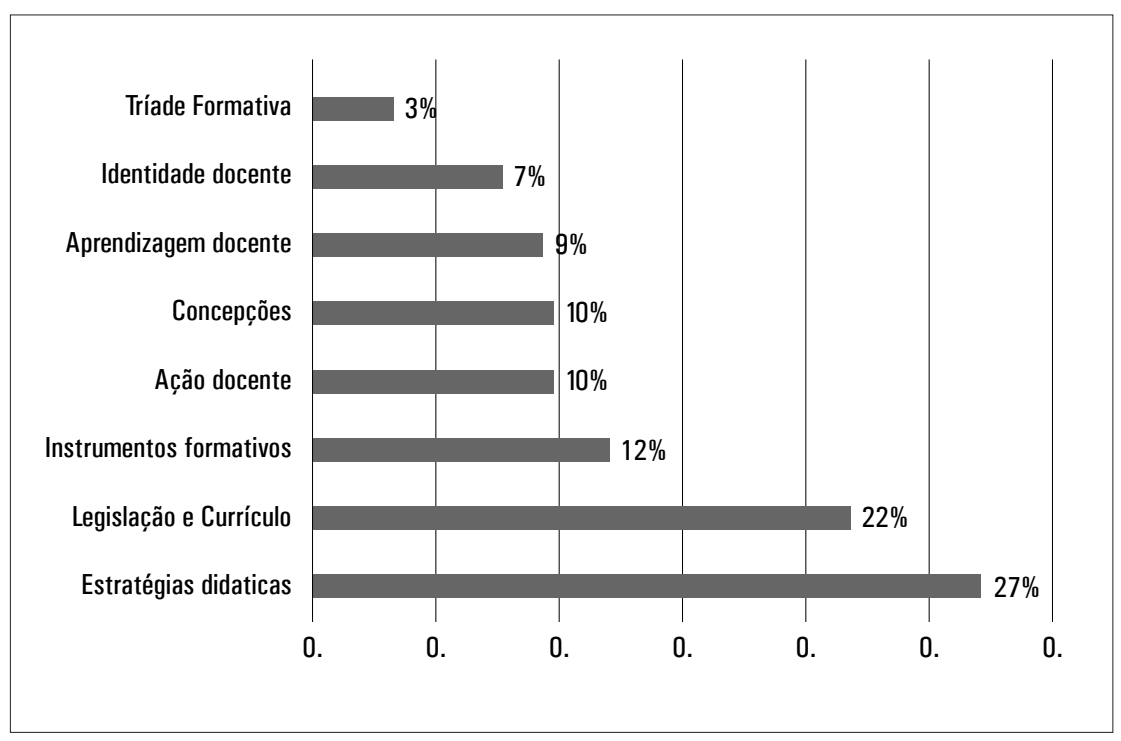

Fonte: elaboração própria. 
É possível constatar, diante das análises realizadas, que as publicações acerca dos estágios supervisionados apresentam as seguintes características: propostas de abordagens a serem executadas ao longo do estágio supervisionado com o uso de diferentes estratégias de ensino e aprendizagem; discussões sobre a legislação e currículo dos estágios; implementação e análise de instrumentos formativos utilizados na disciplina; análise da ação do licenciando durante a execução das regências; pesquisas que relatam concepções/ideias dos licenciandos acerca de diversos temas relacionados à formação docente; artigos que procuram identificar a aprendizagem dos licenciandos para a docência; a constituição da identidade docente ao longo dos estágios e, por fim, artigos que buscam a relação entre os sujeitos envolvidos na tríade formativa do estágio.

Das 8 categorias estabelecidas, 6 delas possuem como foco central da investigação o licenciando, a categoria de Legislação e currículo privilegia discussões teóricas e de cunho curricular, e a categoria C8 - Tríade formativa, preocupa-se com a interação entre os sujeitos envolvidos na formação do licenciando, os orientadores - docentes universitários e os professores regentes das escolas campo de estágio. Essa categoria apresentou a menor quantidade de trabalhos (3 artigos), justificando a necessidade de pesquisas que investiguem o estágio supervisionado em sua totalidade, sob os diferentes aspectos, uma vez que as interações promovidas entre os sujeitos são fundamentais para a formação docente.

Outra consideração a ser realizada advém do fato da predominância das categorias C1 e C2 nas publicações sob essa temática. É possível concluir que metade das pesquisas $(50 \%$ dos artigos) se preocupa em propor estratégias para serem executadas em sala de aula ou discutir teoricamente o campo de estágio supervisionado, bem como a estrutura dos estágios nas instituições de ensino superior. De acordo com o Censo da Educação Superior do INEP (2016), o Brasil possui 7.629 cursos de Licenciatura, o que justifica a relevância de pesquisas acerca do estágio supervisionado, componente curricular obrigatório nestes cursos.

Para além das análises apresentadas e discutidas até o momento, também consideramos nesta investigação a distribuição das pesquisas (instituição dos autores dos artigos) nas diferentes regiões brasileiras. Essa distribuição é apresentada na Figura 4. 
FIGURA 4. Distribuição das produções de acordo com a região geográfica e 0 eixo temático, no período de 2000-2018

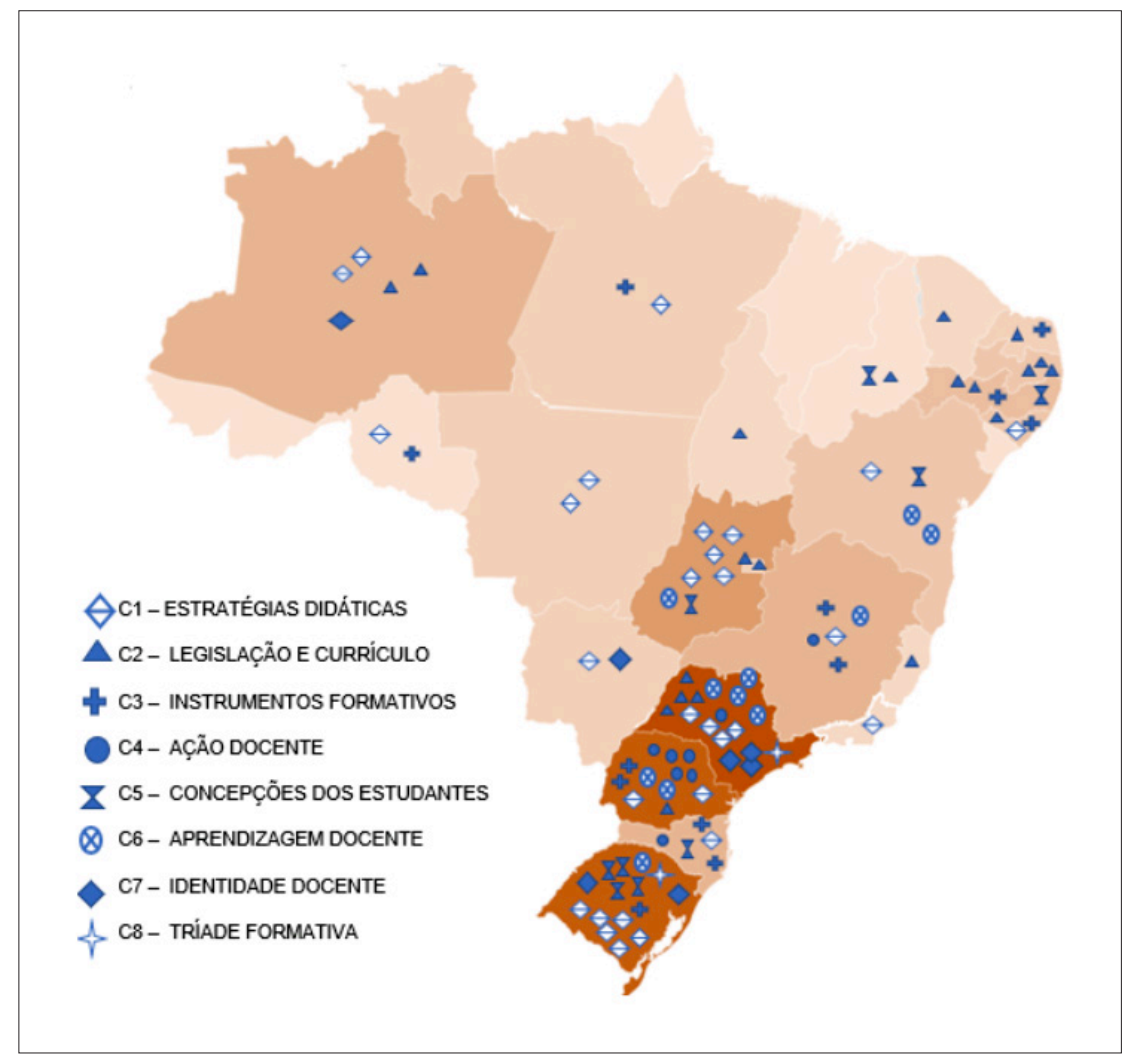

Fonte: elaboração própria.

Conforme exposto na Figura 4, dos 26 estados brasileiros, 5 não apresentam pesquisas sobre o tema em questão (Acre, Roraima, Amapá, Sergipe e Maranhão). Desses, três estados (Acre, Roraima e Amapá) estão localizados na região Norte do País, a qual possui a menor quantidade de pesquisas que versam sobre o estágio supervisionado no ensino de Ciências comparado com as demais regiões do País (10\%). Destaca-se nessa região, a Universidade Estadual do Amazonas (UEA) como a instituição que mais produziu sobre essa temática.

Em contrapartida, a região Sul concentra a maior quantidade de pesquisas $(34 \%)$, seguida pela região Sudeste $(25 \%)$, Nordeste $(17 \%)$ e Centro-oeste $(14 \%)$. Apesar desta investigação pautar-se em periódicos nacionais, foi possível identificar algumas produções (4 artigos) de pesquisadores de outros países como Portugal e Canadá. 
Outro fator a considerar é que, ainda que a região Sul concentre a maior quantidade de pesquisas sobre estágio supervisionado, o estado de São Paulo possui o maior número de pesquisas na área, pouco à frente do Paraná, Rio Grande do Sul e Goiás (estado que se sobressai na região Centro-oeste). Já a região Nordeste, que abrange a maior quantidade de estados, possui uma distribuição homogênea de produções.

Institucionalmente, a Universidade Estadual de São Paulo (USP), a Universidade Estadual de Londrina (UEL), a Universidade de Santa Maria (UFSM) e a Universidade Federal de Goiás (UFG) são as instituições de ensino superior que mais produziram academicamente sobre o estágio supervisionado na formação inicial de professores na área de Ensino de Ciências, representando mais de $1 / 4$ das produções de todo o País.

É possível observar ainda que trabalhos com foco em propostas que fazem uso de diferentes estratégias didáticas (C1) e discussões teóricas acerca do currículo e organização dos estágios (C2) se estendem por todo o País, corroborando para o fato de serem as categorias mais expressivas em quantidade de pesquisas. Entretanto, no que se refere às regiões Norte e Nordeste, destaca-se a predominância de pesquisas que versam sobre Legislação e currículo (C2). Já no estado de Goiás, conduzidas pela UFG, investiga-se mais acerca de estratégias didáticas (C1).

No Paraná, as pesquisas impulsionadas especialmente pela UEL focam a Ação dos estudantes (C4), e no Rio Grande do Sul, além da proposição de estratégias (C1), também se destaca o levantamento de concepções dos estagiários acerca de aspectos relativos à docência (C5). As produções sobre Aprendizagem docente (C6) e Identidade docente (C7) são mais proeminentes no estado de São Paulo. Essa regionalização das categorias são características de grupos de pesquisa constituídos e ativos relativos aos programas de Pós-Graduação da área de Ensino de Ciências.

Fica evidente que os estados que possuem mais produções, São Paulo, Paraná e Rio Grande do Sul, além de possuírem grupos de pesquisa que seguem linhas específicas de investigação sobre a formação de professores, o que acaba por tratar de questões relativas ao estágio supervisionado, também apresentam discussões que resvalam em aspectos comuns, uma vez que apresentam produções distribuídas em 6 categorias das 8 que encontramos na análise do corpus. Esse dado revela certa congruência ao tratar de aspectos relacionados ao estágio supervisionado.

No que concerne às pesquisas específicas da área de Química foco de investigação futura - foram encontrados 18 artigos publicados 
em 10 periódicos distintos, no período de 2008-2018. Quanto à distribuição geográfica, as produções sobre estágio nos cursos de Licenciatura em Química seguem a tendência nacional de abrangência da região Sul e Sudeste totalizando 13 artigos. As regiões Norte e Centro-Oeste possuem apenas dois trabalhos cada e a região Nordeste, representado pelo estado da Bahia apresenta apenas um trabalho. A Figura 5 demonstra a distribuição de artigos por eixos temáticos.

FIGURA 5. Distribuição percentual dos artigos de formação inicial de professores de Química por eixo temático

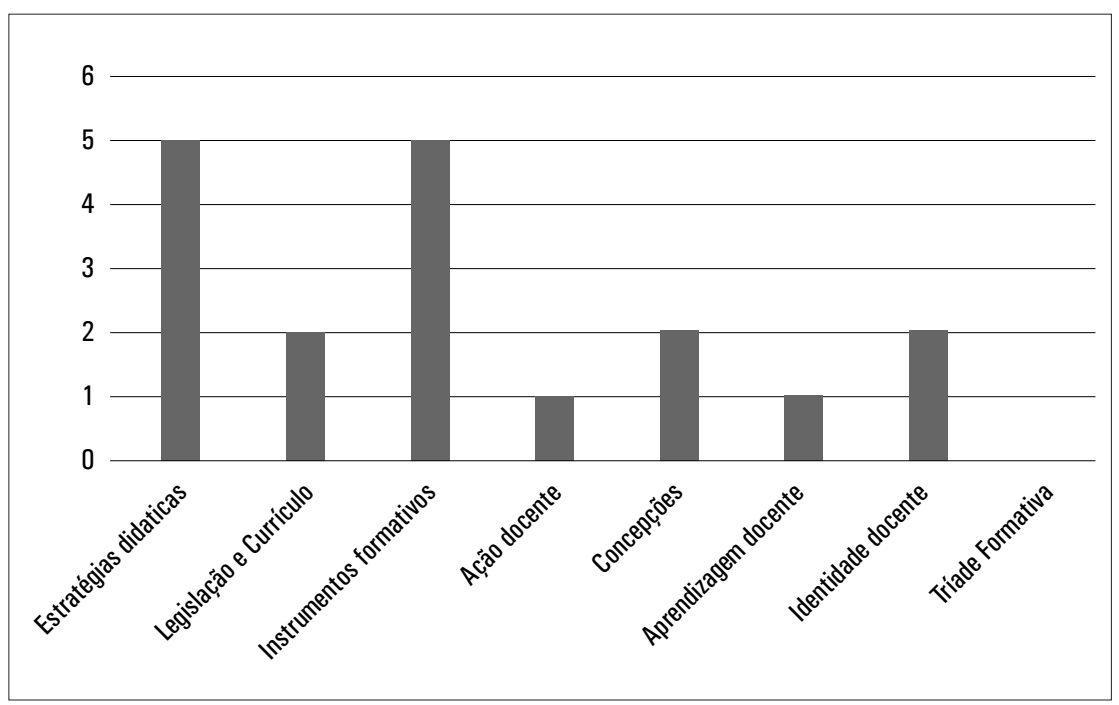

Fonte: elaboração própria.

É possível observar que há uma predominância das pesquisas sobre as categorias C1 - estratégias didáticas e C3 - Instrumentos formativos, com 5 artigos em cada uma, abarcando mais de $60 \%$ do total de artigos para a formação de professores de Química.

As abordagens que fazem uso de estratégias didáticas (C1) discorrem sobre várias delas: textos de divulgação científica, blogs, contextualização na abordagem CTSA aliada a experimentação e metodologia por projetos. Já os Instrumentos formativos (C3) empregados para auxiliar os estagiários e professores formadores para avaliar a aprendizagem docente giram em torno de práticas de escrita. Dos 5 trabalhos pertencentes a essa categoria, 4 tratam sobre narrativas produzidas pelos licenciandos; livro de relatos ou diários de campo. O artigo IENCI_4 difere dos demais por apresentar a articulação do microensino com a autoscopia bifásica durante a realização dos estágios para auxiliar na aprendizagem dos futuros professores. 
As categorias Legislação e currículo (C2), Concepções de estagiários (C5) e Identidade docente (C7) possuem a mesma quantidade de trabalhos, 2 artigos cada. Pesquisas que investigam a Ação docente (C4) e Aprendizagem dos futuros docentes do curso de licenciatura em Química (C6) estão em menor quantidade contando com apenas um trabalho em cada categoria. Somado a isso, há a ausência de trabalhos na categoria C8 - Tríade formativa, indicando que não há pesquisas que abordam a relação dos estagiários com os seus professores (formador ou supervisor) na área de Química.

\section{CONSIDERAÇ̃̃ES FINAIS}

Dada a importância do estágio supervisionado como componente curricular obrigatório nos cursos de licenciatura e diante da problemática aqui estabelecida - compreender aspectos que estão sendo pautados e discutidos, por pesquisadores/educadores acerca dos estágios supervisionados, em artigos publicados em periódicos nacionais da área de Ensino de Ciências - ao analisarmos os 87 artigos selecionados destacamos as seguintes considerações:

Foram encontradas produções no período de 2000-2018, com contribuição em maior quantidade da área de Ciências Biológicas. O desenvolvimento do campo de pesquisa se acentuou na última década (2008-2018), decorrente da implantação de políticas públicas para a formação dos futuros professores.

Para uma melhor compreensão acerca das tendências, preocupações e anseios que interessam aos pesquisadores/professores da área de Ensino de Ciências, encontramos 8 categorias que expressam os principais aspectos abordados nos trabalhos analisados, a saber: Estratégias didáticas (C1); Legislação e currículo (C2); Instrumentos formativos (C3); Ação docente (C4); Concepções dos estagiários (C5); Aprendizagem docente (C6); Identidade docente (C7) e Tríade formativa (C8). Dessas, 6 categorias (C1, C3, C4, C5, C6, C7) apresentam o licenciando como objeto de estudo e foco da investigação, enquanto a categoria C2 - Legislação e currículo - privilegia discussões a respeito da organização curricular e institucional da disciplina de estágio supervisionado, e C8 - Tríade formativa - que considera o estágio como espaço de formação coletiva, com o necessário envolvimento dos professores (orientador e supervisor) na formação dos estagiários.

Logo, as pesquisas recaem sobre o estagiário, o principal agente a ser considerado, entretanto não há um pensamento majoritário do estágio como espaço coletivo, em que a organização e interações 
também pesam na formação do futuro professor, corroborado pelo fato da categoria C8 possuir a menor quantidade de trabalhos, representando $3 \%$ das pesquisas.

Além disso, $59 \%$ das pesquisas debruçam-se sobre sugestões de estratégias para serem executadas em sala de aula (C1), discussões teóricas sobre o campo do estágio (C2), concepções prévias (C5); no sentido de apresentar proposições a respeito da condução dos estágios. Em contrapartida, 26\% ocupa-se em investigar a ação dos estudantes em sala (C4) e as competências mobilizadas durante a realização do estágio (C6), ou seja, investigar como os estagiários estão compreendendo a prática docente, e se estão de fato, colocando em práticas as ideias propostas.

No que se refere à área específica de Química, de maneira geral a tendência se mantém com uma quantidade expressiva de pesquisas propositivas e uma menor quantidade de pesquisas avaliativas.

Foi possível observar também que existe uma preocupação por parte dos pesquisadores, disseminados nas diversas regiões do Brasil, quanto à melhoria da formação docente, considerando investigações acerca do estágio supervisionado. Os grupos de pesquisa de algumas universidades impulsionam as produções, fazendo com que as regiões Sul e Sudeste se sobressaiam em termos de variedade de aspectos a serem discutidos e em termos de quantidade. A realização desta investigação nos permitiu visualizar uma discussão plural em torno dos diferentes eixos/categorias estabelecidas em torno da temática - Estágios Supervisionados nos cursos de licenciatura da área de Ensino de Ciências -, suscitando reflexões acerca do cenário de pesquisas nesta área e de lacunas ainda a serem investigadas com a finalidade de colocar em evidência a formação docente.

Destacamos também, que ao longo do mapeamento não encontramos nenhuma outra pesquisa que apresentasse um panorama sobre o desenvolvimento dos estágios supervisionados nos cursos de formação de professores. Compreendemos assim que este mapeamento fornece subsídios para o entendimento das tendências, preocupações e anseios que interessam aos pesquisadores/professores da área.

\section{REFERÊNCIAS}

ALMEIDA, D. P.; TERÁN, A. F. O estágio docência na formação do mestre em ensino de Ciências na Amazônia: relato de experiência. ARETÉ, v. 6, n. 10, p. 98-106, 2013.

ASSAI, N. D. S.; ARRIGO, V.; BROIETTI, F. C. D. Uma proposta de mapeamento em periódicos nacionais da área de ensino de ciências. Revista de Produtos Educacionais e Pesquisa em Ensino - REPPE, v. 2, n.1, p. 150-166, 2018. 
BARDIN, L. Análise de conteúdo. São Paulo: Edições 70, 229p. 2011.

BRASIL. Conselho Nacional de Educação. Define as Diretrizes Curriculares Nacionais para a formação inicial em nível superior (cursos de licenciatura, cursos de formação pedagógica para graduados e cursos de segunda licenciatura) e para a formação continuada. Resolução CNE/CP n. 02/2015, de $1^{\circ}$ de julho de 2015. Brasília, Diário Oficial [da] República Federativa do Brasil, seção 1, n. 124, p. 8-12, 02 de julho de 2015.

BRASIL. Decreto n. 6.755, de 29 de janeiro de 2009. Institui a Política Nacional de Formação de Profissionais do Magistério da Educação Básica, disciplina a atuação da Capes no fomento a programas de formação inicial e continuada e dá outras providências. Diário Oficial [da] República Federativa do Brasil, Poder Executivo, Brasília, DF, 30 jan. 2009a.

BRASIL. Ministério da Educação (MEC). Portaria normativa n. 9, de 30 de junho de 2009. Institui o Plano Nacional de Formação dos Professores da Educação Básica no âmbito do Ministério da Educação. Diário Oficial [da] República Federativa do Brasil, Poder Executivo, Brasília, DF, 1 jul. 2009b.

BRASIL. Conselho Nacional de Educação. Diretrizes Curriculares Nacionais para a Formação de Professores da Educação Básica, em nível superior, curso de licenciatura, de graduação plena. Parecer CNE/CP n. 9/2001, de 20 de maio de 2001. Brasília. Diário Oficial [da] República Federativa do Brasil, 18 de janeiro de 2002, Seção 1, p. 31.

BRASIL. Conselho Nacional de Educação. Diretrizes Curriculares Nacionais para a Formação de Professores da Educação Básica, em nível superior, curso de licenciatura, de graduação plena. Parecer CNE/CP n. 9/2001, de 20 de maio de 2001. Brasília. Diário Oficial [da] República Federativa do Brasil, 18 de janeiro de 2002, Seção 1, p. 4.

BRASIL. Lei de Diretrizes e Bases da Educação Nacional. Lei número 9394, 20 de dezembro de 1996.

BRASIL. Orientações Educacionais Complementares aos Parâmetros Curriculares Nacionais (PCN+). Ciências da natureza, matemática e suas tecnologias. Brasília: MEC, 2006.

BURIOLLA, M. A. F. O estágio supervisionado. São Paulo: Cortez, 1995. 196 p.

CARRETERO, M. Constructivismo y Educación. Zaragoza: Editorial Luis Vives, 1993.

DIAS, S. M. A.; MASCARENHAS FILHO, A. S.; ANDRADE, A. P. O. V. Revelações do trabalho do professor de inglês no Ensino Médio. Ensino \& Pesquisa, v. 15, n. 14, p. 88-99, 2017.

DUBAR, C. A socialização: construção das identidades sociais e profissionais. Porto: Porto Editora, 2009.

FIORENTINI, D.; CASTRO, F. C. Tornando-se professores de matemática: O caso de Allan em Prática de Ensino e Estágio Supervisionado. In: FIORENTINI, D (org.). Formação de professores de Matemática: explorando novos caminhos com outros olhares. Campinas, SP; Mercado das letras, p. 121-156, 2003.

GERVAIS, C. A organização dos estágios e o acompanhamento do desenvolvimento profissional dos estagiários em Quebec. Cadernos de Educação, Pelotas, v. 46, p. 23-44, 2013.

INSTITUTO NACIONAL DE ESTUDOS E PESQUISAS EDUCACIONAIS ANÍSIO TEIXEIRA. Sinopse Estatística da Educação Superior 2015. Brasília: Inep, 2016. Disponível em: <http://portal.inep.gov.br/basica-censo-escolar-sinopse-sinopse>. Acesso em: 28 mai. 2018. 
LABURU, C. E.; ARRUDA, S. de M.; NARDI, R. Pluralismo metodológico no ensino de ciências. Ciênc. educ. (Bauru), Bauru, v. 9, n. 2, p. 247-260, 2003.

LUCKESI, C. C. O que é mesmo o ato de avaliar a aprendizagem? Pátio, Rio Grande do Sul, n. 12, p. 6-11, 2000.

MARTINS, T. R. M.; SLAVEZ, M. H. C. Um estudo sobre programas de iniciação à prática profissional de professores no Brasil: o PIBID e o estágio de residência. Revista Ensino \& Pesquisa, v. 13, n. 01 (suplemento) p. 29-41, 2015.

MASETTO, M. T. Competência pedagógica do professor universitário. São Paulo: Summus, 2003.

PASSOS, L. F. De espaços e lugares de formação: o estágio, as narrativas e os conhecimentos profissionais dos futuros professores. Cadernos de Educação, n. 46, p. 45-61, 2013.

PIMENTA, S. G.; LIMA, M. S. L. Estágio e docência. 3. ed. São Paulo: Cortez, 2012.

SANTOS, R. P. dos. A folha seca, a pedra, a maçã e o Sputnik - algumas considerações sobre a gênese dos conceitos de peso e massa. Acta Scientiae, v. 7, n. 2, p. 7-22, 2005.

SILVA, A. P. T. B.; BASTOS, H. B. N. Uma proposta metodológica para o estágio curricular supervisionado na EAD: articulações entre CEK e Grupo Cooperativo. Ciência \& Educação, Bauru, v. 23, n. 3, p. 741-757, 2017.

SILVA JÚNIOR, A. F. Estágio supervisionado na formação de professores de história: relação teoria e prática. Interfaces da Educação, v. 6, n. 16, p. 103-117, 2015.

TARDIF, M.; RAYMOND, D. Saberes, tempo e aprendizagem do trabalho no magistério. Educação \& Sociedade, ano XXI, n. 73, 2000.

ZANON, L. B. Interações de licenciandos, formadores e professores na elaboração conceitual da prática docente: módulos triádicos na licenciatura de química. 2003. $282 \mathrm{f}$. Tese (Doutorado em Educação) - Faculdade de Ciências Humanas, Universidade Metodista de Piracicaba, Piracicaba, 2003.

\section{NOTAS}

${ }^{1}$ Estamos considerando, neste artigo, pesquisas da área de Ensino de Ciências, aquelas advindas das seguintes áreas de formação: Física, Química e Biologia.

${ }^{2}$ Entendemos como núcleo de sentido, a expressão, ou o trecho que responde mais objetivamente à questão de pesquisa ou, referente ao tema da investigação

Submetido: $14 / 06 / 2018$

Aprovado: 10/09/2018

Contato:

Natany Dayani de Souza Assai

Universidade Estadual de Londrina (UEL)

Rodovia Celso Garcia Cid - Pr 445 Km 380

Campus Universitário

Londrina | PR | Brasil

CEP 86.057-970 
APÊNDICE

LISTA DAS REFERÊNCIAS DOS ARTIGOS CONSTITUINTES DO CORPUS E SUAS RESPECTIVAS CODIFICAÇÕES

\begin{tabular}{|c|c|}
\hline REFERÊNCIA & CODIFICAÇÃO \\
\hline $\begin{array}{l}\text { ABDALLA, M. F. B. A relação teoria e } \\
\text { prática no campo do estágio. Revista de } \\
\text { Educação PUC-Campinas, Campinas, } \\
\text { n. 26, p. 53-62, 2009. }\end{array}$ & $\begin{array}{l}\text { REV_EDU_PUC_ } \\
\text { CAM2009_1 }\end{array}$ \\
\hline $\begin{array}{l}\text { AGUIAR, T. C.; FRANCISCO JÚNIOR, } \\
\text { W. E. Ações e Reflexões durante o Estágio } \\
\text { Supervisionado em Química: algumas notas } \\
\text { autobiográficas. Química nova na escola, } \\
\text { São Paulo, v. 35, n. 4, p. 283-291, } 2013 .\end{array}$ & QNESC2008_8 \\
\hline $\begin{array}{l}\text { ALMEIDA, W. A.; GHEDIN, E. A } \\
\text { fertilidade do conceito de professor } \\
\text { pesquisador a partir da aplicação de uma } \\
\text { metodologia no processo de estágio. Areté } \\
\text { - Revista Amazônica de Ensino de Ciências, } \\
\text { Manaus, v. 2, n. 3, p. 106-113, } 2009 \text {. }\end{array}$ & ARETÉ2009_1 \\
\hline $\begin{array}{l}\text { ARAÚJO, K. C. L. C. O debate da } \\
\text { política curricular e os sentidos do } \\
\text { estágio supervisionado (1996-2006): } \\
\text { uma análise a partir da teoria do } \\
\text { discurso. Educação em Revista, Belo } \\
\text { Horizonte, n. 34, 2018. Disponível em } \\
\text { <http://www.scielo.br/scielo.php?pid } \\
=\text { S010246982018000100132\& } \\
\text { script=sci_abstract\&tlng=pt>. } \\
\text { Acesso em: } 25 \text { mai. } 2018 \text {. }\end{array}$ & EDU_REVISTA2018_1 \\
\hline
\end{tabular}




\begin{tabular}{|c|c|}
\hline $\begin{array}{l}\text { ARRIGO, V.; LORENCINI JÚNIOR, A.; } \\
\text { BROIETTI, F. C. D. A autoscopia bifásica } \\
\text { integrada ao microensino: uma estratégia } \\
\text { de intervenção reflexiva na formação de } \\
\text { professores de química. Investigações } \\
\text { em Ensino de Ciências, Porto Alegre, v. } \\
\text { 22, n. 1, p. 01-22, } 2017 \text {. }\end{array}$ & IENCI2017_4 \\
\hline $\begin{array}{l}\text { ARRUDA, S. M.; BACCON, A. L. } \\
\text { P. O professor como um "lugar": } \\
\text { uma metáfora para a compreensão da } \\
\text { atividade docente. Ensaio Pesquisa em } \\
\text { Educação em Ciências, Belo Horizonte, } \\
\text { v. } 9 \text {, n. 1, p. 112-131, } 2007 \text {. }\end{array}$ & ENSAIO2007_2 \\
\hline $\begin{array}{l}\text { ARRUDA, S. M.; LIMA, J. P. C.; PASSOS, } \\
\text { M. M. Um novo instrumento para a } \\
\text { análise da ação do professor em sala de } \\
\text { aula. Revista Brasileira de Pesquisa em } \\
\text { Educação em Ciências, Belo Horizonte, } \\
\text { v. } 11 \text { n. } 2 \text {, p. } 139-160,2011 \text {. }\end{array}$ & RBPEC2011_3 \\
\hline $\begin{array}{l}\text { BACCON, A. L. P.; ARRUDA, S. M. Os } \\
\text { saberes docentes na formação inicial do } \\
\text { professor de Física: elaborando sentidos } \\
\text { para o estágio supervisionado. Ciência \& } \\
\text { Educação, Bauru, v. 16, n. 3, p. } 507-524 \text {, } \\
2010 \text {. }\end{array}$ & CIEDU2010_4 \\
\hline $\begin{array}{l}\text { BAPTISTA, L. V.; AZEVEDO, R. B.; } \\
\text { GOLDSCHMIDT, A. I.; Tríade basilar: } \\
\text { uso das estratégias, a inclusão da história } \\
\text { e filosofia da biologia e a confecção de } \\
\text { material didático. Amazônia - Revista } \\
\text { de Educação em Ciências e Matemática, } \\
\text { Belém, v. } 12 \text { n. } 23 \text {, p. 31-43, } 2015 \text {. }\end{array}$ & AMAZÔNIA2015_4 \\
\hline
\end{tabular}


BARBOSA, F. A. et al. Abordagem "Ciência, Tecnologia e Sociedade" (CTS) no ensino de Física: uma proposta na formação inicial de professores. Revista

ENSINO_E PESQUISA2017_1

Ensino \& Pesquisa, União da Vitória, v. 15, n. 1, p. 158-178, 2017.

BARCELOS, C. F. S.; MANSO, M. H. S. O estágio supervisionado nos cursos de licenciatura: algumas considerações críticas. Cadernos de Pesquisa em Educação, CADERNOS_PES_ EDU2010

Vitória, v. 16, n. 31, p. 146-172, 2010.

BARRETO, E. S.; OLIVEIRA, M.

M.; ARAÚJO, M. L. F. O estágio supervisionado obrigatório na formação do professor de Ciências e Biologia: perspectivas de licenciandos e orientadores.

REV_TEM_ ESPA2015_1

\section{Revista Tempos e Espaços em}

Educação, São Cristóvão, v. 8, n. 16, 2015.

BARREYRO, G. B. et al. Uma proposta inovadora de estágios para os professores de ciências: a experiência do curso de licenciatura em Ciências da Natureza (EACH-USP) em São Paulo, Brasil. Experiências em Ensino de Ciências, Cuiabá, v. 5, n. 3, p. 83-93, 2010.

EENCI2010_1

BARRO, M. R.; BAFFA, A.; QUEIROZ, S. L. Blogs na Formação Inicial de professores de Química. Química nova na escola, São QNESC2014_7 Paulo, v. 36, n. 1, p. 4-10, 2014. 


\begin{tabular}{|c|c|}
\hline $\begin{array}{l}\text { BARROS, J. D. S.; SILVA, M. F. P.; } \\
\text { VÁSQUEZ, S. F. A prática docente } \\
\text { mediada pelo estágio supervisionado. Atos } \\
\text { de pesquisa em educação, Blumenau, v. } \\
\text { 6, n. 2, p. 510-520, } 2011 .\end{array}$ & $\begin{array}{l}\text { ATOS_DE_ } \\
\text { PESQUISA2011_1 }\end{array}$ \\
\hline $\begin{array}{l}\text { BROIETTI, F. C. D.; STANZANI, E. } \\
\text { L. Os estágios e a formação inicial de } \\
\text { professores: experiências e reflexões no } \\
\text { curso de Licenciatura em Química da } \\
\text { UEL. Química nova na escola, São } \\
\text { Paulo, v. 38, n. 3, p. 306-317, } 2016 .\end{array}$ & QNESC2016_6 \\
\hline $\begin{array}{l}\text { CABRAL, W. A.; FLÔR, C. C. C. (Re) } \\
\text { pensando as práticas de escrita na } \\
\text { disciplina de estágio supervisionado em } \\
\text { Química: com a palavra, os estagiários. } \\
\text { Ensaio Pesquisa em Educação em } \\
\text { Ciências, Belo Horizonte, v. 18, n. 3, p. } \\
\text { 161-174, 2016. }\end{array}$ & ENSAIO2016_4 \\
\hline $\begin{array}{l}\text { CARMO-OLIVEIRA, R.; CARVALHO, } \\
\text { D. Planejando aulas de botânica a partir de } \\
\text { uma provocação. Revista Brasileira de } \\
\text { Ensino de Ciência e Tecnologia, Ponta } \\
\text { Grossa, v. 8, n. 4, p. 208-220, } 2015 \text {. }\end{array}$ & RBECT2015_2 \\
\hline $\begin{array}{l}\text { CARVALHO, A. M. P. A influência das } \\
\text { mudanças da legislação na formação } \\
\text { dos professores: as } 300 \text { horas de estágio } \\
\text { supervisionado. Ciência \& Educação, } \\
\text { Bauru, v. 7, n. 1, p. 113-122, } 2001 .\end{array}$ & CIEDU2001_1 \\
\hline $\begin{array}{l}\text { CHRISTINO, V. C. L.; FERREIRA, M. } \\
\text { Formação de Professores, Discursos e } \\
\text { Práticas de Ingressantes na Docência } \\
\text { em Química na Educação Básica. Acta } \\
\text { Scientiae, Canoas, v. } 15 \text { n. 1, p. 172-190, } \\
2013 .\end{array}$ & ACTA2013_1 \\
\hline
\end{tabular}


CONFORTIN, R.; CAIMI, F. E.

Constituição e mobilização de saberes

docentes: perscrutando práticas de professores de Biologia no Ensino Médio.

RBPEC2017_2

\section{Revista Brasileira de Pesquisa em}

Educação em Ciências, Belo Horizonte, v. 1, n. 1, p. 157-181, 2017.

CORREIA, D.; SAUERWEIN, I. P.

S. As leituras de textos de divulgação científica feitas por licenciandas no estágio supervisionado em Física. Revista Brasileira de Ensino de Física, São Paulo, v. 39, n. 3, 2017. Disponível em REV_BRA_ENS FÍSICA2017_1

$<$ http://www.scielo.br/scielo.php?script

=sci_arttext\&pid $=$ S180611172017

$000300501 \& \operatorname{lng}=$ en $\& \mathrm{nrm}=$ iso $>$

Acesso em: 25 mai. 2018.

COSTA, J. S. O estágio supervisionado no curso de Biologia: desafios e possibilidades. Debates em educação, Maceió, v. 8, n. 15, 2016. Disponível em $<$ http://www.seer.ufal.br/index.

DEBATES2016_2 $\mathrm{php} /$ debateseducacao/article/ view/2239/1900>. Acesso em: 25 mai. 2018.

CUNHA, R. S. et al. Formação inicial docente e suas relações dentro do âmbito escolar. Ciência \& Educação, v. 22, n. 3, CIEDU2016_3 p. 585-596, 2016. 


\begin{tabular}{|l|l|}
\hline $\begin{array}{l}\text { ESTEVES, E.; LEITE, L. Expectativas } \\
\text { e receios dos alunos relativamente } \\
\text { a estágio um estudo centrado na } \\
\text { licenciatura em ensino de Física e Química } \\
\text { da universidade do Minho. Revista } \\
\text { Brasileira de Pesquisa em Educação } \\
\text { em Ciências, Belo Horizonte, v. 4, n. 1. p. } \\
\text { 12-30, 2004. }\end{array}$ & \\
\hline $\begin{array}{l}\text { FERNANDES, C. M. B. O espaço-tempo } \\
\text { do estágio nos movimentos do curso: }\end{array}$ & \\
interrogantes, desafios e a construção de \\
territorialidades. Cadernos de Educação, \\
Pelotas, v. 37, p. 325-345, 2010.
\end{tabular}


GAUCHE, R. et al. Formação de professores de Química: concepções e proposições. Química nova na escola, QNESC2008_5 São Paulo, v. 27, p. 26-29, 2008.

GENOVESE, L. G. R.; QUEIROZ, J. R. O.; CATILHO, D. D. Incorporação do habitus de homo magister no interior do estágio colaborativo em Física: um olhar sobre a relação entre professor supervisor

ENSINO_EM_ REVISTA2015_1 e estagiário. Ensino em Re-Vista, Uberlândia, v. 22, n. 2, p. 311-332, 2015.

GERVAIS, C. A organização dos estágios e o acompanhamento do desenvolvimento profissional dos estagiários em Quebec.

Cadernos de Educação, Pelotas, v. 46, p.

CADERNOS_DE_ EDU2013_2 23-44, 2013.

GOLDSCHMIDT, A. I. Professores como cerrado: a cada chuva o esplendor da primavera. Amazônia: Revista de Educação em Ciências e Matemática, Belém, v. 12, n. 24, p. 26-38, 2016.

GOLDSCHMIDT, A. I.; CASTRO, T. F. Aulas práticas em Ciências: concepções de estagiários em licenciatura em Biologia e a realidade durante os estágios.

AMAZÔNIA2016_2

Amazônia - Revista de Educação em Ciências e Matemática, Belém, v. 13, n. 25, p. 116-134, 2016.

AMAZÔNIA2016_3 


\begin{tabular}{|l|l|}
\hline $\begin{array}{l}\text { GOLDSCHMIDT, A. I. } \text { et al. Entre } \\
\text { riscos e rabiscos: concepços sobre a } \\
\text { imagem docente. Ensino de Ciências e } \\
\text { Tecnologia em Revista, Santo Ângelo, v. } \\
\text { 6, n. 1, p. 24-36, 2016. }\end{array}$ & ENCITEC2016_1 \\
\hline $\begin{array}{l}\text { GONÇALVES, F. P. et al. O diário de aula } \\
\text { coletivo no Estágio da Licenciatura em }\end{array}$ & \\
Química: dilemas e seus enfrentamentos. \\
$\begin{array}{l}\text { Química nova na escola, São Paulo, n. } \\
\text { 30, p. 42-48, 2008. }\end{array}$ & QNESC2008_3 \\
\hline $\begin{array}{l}\text { GONÇALVES, F. P.; FERNANDES, C. S. } \\
\text { Narrativas acerca da prática de ensino de } \\
\text { Química: um diálogo na formação inicial } \\
\text { de professores. Química nova na escola, } \\
\text { São Paulo, v. 32, n. 2, p. 120-127, 2010. }\end{array}$ & \\
\hline $\begin{array}{l}\text { GUIMARÃES, S. S. M.; PARANHOS, } \\
\text { R. D. Estágio na licenciatura em Ciências } \\
\text { como uma estratégia. Revista Docência } \\
\text { do Ensino Superior, Belo Horizonte, v. } \\
\text { 6, n. 2, p. 89-114, 2016. }\end{array}$ & \\
\hline $\begin{array}{l}\text { GUERTA, R. S.; CAMARGO, C. } \\
\text { C. Comunidade de aprendizagem } \\
\text { da docência em estágio curricular } \\
\text { obrigatório: aprendizagens evidenciadas } \\
\text { pelos licenciandos. Ciência \& Educação, } \\
\text { Bauru, v. 21, n. 3, p. 605-621, 2015. }\end{array}$ & \\
\hline
\end{tabular}


LANGHI, R.; NARDI, R. Interpretando reflexões de futuros professores de Física sobre sua prática profissional durante a formação inicial: a busca pela construção IENCI2011_5 da autonomia docente. Investigações em Ensino de Ciências, Porto Alegre, v. 16, n. 3, p. 403-424, 2011.

LOURENÇO, A. B.; ABIB, M. L. S.; MURILLO, F. J. Aprendendo a ensinar e a argumentar: saberes de argumentação docente na formação de futuros professores de Química. Revista

RBPEC2016_1

Brasileira de Pesquisa em Educação em Ciências, Belo Horizonte, v. 16. n. 2. p. 295-316. 2016.

MAKNAMARA, M. Narrativas (auto) biográficas e necessidades formativas de futuros docentes de Ciências: reflexões preliminares para um objeto em construção.

REV_TEM_

ESPA2015_2

\section{Revista Tempos e Espaços em}

Educação, São Cristóvão, v. 8, n. 16, 2015.

MANFREDO, E. C. G. Metodologia de projetos e formação de professores: uma experiência significativa na prática de ensino de Ciências Naturais. EENCI2006_3 Experiências em Ensino de Ciências, Cuiabá, v. 1, n. 3, p. 45-57, 2006.

MARTINS, A. F. P. Estágio supervisionado em Física: o pulso ainda pulsa... Revista Brasileira de Ensino de Física, São Paulo, v. 31, n. 3, p. 3402.1REV_BRA_ENS FÍSICA2009_2 3402.7, 2009. 


\begin{tabular}{|c|c|}
\hline $\begin{array}{l}\text { MELO, M. J. C.; ALMEIDA, L. A. A. } \\
\text { Estágio supervisionado e prática docente: } \\
\text { sentidos das produções discursivas da } \\
\text { ANPEd, BDTD e EPENN. Revista } \\
\text { Eletrônica de Educação, São Carlos, v. } \\
\text { 8, n. 3, p. 34-51, 2014. }\end{array}$ & REVEDUC2014_1 \\
\hline $\begin{array}{l}\text { MION, R. A.; ALVES, J. A. P.; } \\
\text { CARVALHO, W. L. P. Implicações } \\
\text { da relação entre Ciência, Tecnologia, } \\
\text { Sociedade e Ambiente: subsídios para } \\
\text { a formação de professores de Física. } \\
\text { Experiências em Ensino de Ciências, } \\
\text { Cuiabá, v. 4, n. 2, p. 47-59, } 2009 .\end{array}$ & EENCI2009_6 \\
\hline $\begin{array}{l}\text { MORAES, C. J. C.; OLIVEIRA, C. M.; } \\
\text { GOLDSCHMIDT, A. I. Elaboração de } \\
\text { estratégias de ensino e uso dos estatutos } \\
\text { do conhecimento: os obstáculos na } \\
\text { construção do conhecimento de Ciências- } \\
\text { Física. Amazônia - Revista de Educação } \\
\text { em Ciências e Matemática, Belém, v. 13, n. } \\
\text { 28, p. 23-37, } 2017 .\end{array}$ & AMAZÔNIA2017_5 \\
\hline $\begin{array}{l}\text { MUNIZ, G. F. F. Q. et al. O papel do } \\
\text { professor na interação e construção do } \\
\text { conhecimento em aulas de Ciências. } \\
\text { UNOPAR Científica, Ciências } \\
\text { Humanas e Educação, Londrina, v. 15, } \\
\text { número especial, p. 381-387, } 2014 \text {. }\end{array}$ & UNOPAR2014_1 \\
\hline $\begin{array}{l}\text { OLIVEIRA, L. C. V. As contribuições do } \\
\text { estágio supervisionado na formação do } \\
\text { docente-gestor para a educação básica. } \\
\text { Ensaio Pesquisa em Educação em } \\
\text { Ciências, Belo Horizonte, v. 11, n. } 2 \text {, p. } \\
\text { 241-258, 2009. }\end{array}$ & ENSAIO2009_1 \\
\hline
\end{tabular}


OLIVEIRA, E. S.; GHEDIN, E. O estágio vinculado à pesquisa na formação de professores de Ciências nas séries iniciais do ensino fundamental. Areté ARETÉ2009_5 Revista Amazônica de Ensino de Ciências, Manaus, v. 2, n. 3, p. 174-181, 2009.

OLIVEIRA, M. L.; FARIA, J. C. N. M. Formação inicial de professores: desafios e possibilidades do ensino de reprodução e sexualidade no estágio curricular IENCI2011_2 supervisionado. Investigações em Ensino de Ciências, Porto Alegre, v. 16, n. 3, p. 509-528, 2011.

PASSOS, C. G.; DEL PINO, J. C. Efeitos das ações formativas e das concepções epistemológicas nas práticas docentes de uma futura professora de Química. Revista Brasileira de Ensino de Ciência e Tecnologia, Ponta Grossa, v. 3, n. 3, p. 181-212, 2015.

PASSOS, M. M.; MAISTRO, V. I. A.; ARRUDA, S. M. A relação com a docência no estágio supervisionado do curso em Ciências Biológicas. Revista

RBECT2015_3

Ensino \& Pesquisa, União da Vitória, v. 14, n. 2, p. 99-127, 2016.

PEREIRA, L. G. A.; AZEVEDO, R. O. M. Laboratório móvel: possibilidade de contextualizar a prática pedagógica no ensino de Ciências. Areté - Revista Amazônica de Ensino de Ciências, Manaus, v. 7, n. 12, p. 109-116, Número especial, 2014.

ENSINO_E_ PESQUISA2016_3 


\begin{tabular}{|c|c|}
\hline $\begin{array}{l}\text { PEREIRA, W. S. C.; GHEDIN, E. } \\
\text { O estágio como eixo articulador da } \\
\text { dialogicidade entre teoria e prática na } \\
\text { formação do professor de Ciências. Areté - } \\
\text { Revista Amazônica de Ensino de Ciências, } \\
\text { Manaus, v. 2, n. 3, p. 151-158, } 2009 \text {. }\end{array}$ & ARETÉ2009_2 \\
\hline $\begin{array}{l}\text { PEREIRA, R. F.; FUSINATO, P. A.; } \\
\text { GIANOTTO, D. E. P. A prática pluralista } \\
\text { na formação inicial de professores de } \\
\text { Física. Ensaio Pesquisa em Educação } \\
\text { em Ciências, Belo Horizonte, v. 19, p. } \\
\text { 1-25, } 2017 .\end{array}$ & ENSAIO2017_5 \\
\hline $\begin{array}{l}\text { PEZENTE, M. T.; GIASSI, M. G. } \\
\text { Aprendiz de professora - um relato } \\
\text { sobre a importância do estágio na } \\
\text { formação acadêmica. Criar Educação, } \\
\text { Criciúma, v. 1, n. 1, 2015. Disponível em } \\
\text { <http://periodicos.unesc.net/criaredu/ } \\
\text { article/view/2257/2128>. Acesso em: } 25 \\
\text { mai. 2018. }\end{array}$ & CRIAR2015_1 \\
\hline $\begin{array}{l}\text { QUADROS, A. L. Q. A contribuição } \\
\text { do estágio no entendimento do papel } \\
\text { do professor de Química. Educação \& } \\
\text { Realidade, Porto Alegre, v. 41, n. 3, p. } \\
\text { 889-910, 2016. }\end{array}$ & $\begin{array}{l}\text { EDU_- } \\
\text { REALIDADE2016_1 }\end{array}$ \\
\hline $\begin{array}{l}\text { QUEIROZ, S. L.; FERREIRA, L. N. } \\
\text { A. O estágio curricular supervisionado } \\
\text { em Química como espaço para o } \\
\text { desenvolvimento de atividades didáticas } \\
\text { pautadas no uso de textos de divulgação } \\
\text { científica. Ciência \& Ensino, Campinas, } \\
\text { v. 3, n. 2, p. 32-48, } 2014 \text {. }\end{array}$ & $\begin{array}{l}\text { CIENCIA_E_ } \\
\text { ENS2014_1 }\end{array}$ \\
\hline
\end{tabular}


RAZUCK, R. C. S.; ROTTA, J. C. G.

$\mathrm{O}$ curso de licenciatura em Ciências

Naturais e a organização de seus estágios

CIEDU2014_7

supervisionados. Ciência \& Educação,

Bauru, v. 20, n. 3, p. 739-750, 2014.

REGINA, V. B. et al. Concepções e práticas sobre oficina pedagógica de licenciandos em Ciências Biológicas.

EENCI2016_4

Experiências em Ensino de Ciências, Cuiabá, v. 11, n. 2, p. 106-112, 2016.

RETONDO, C. G.; SILVA, G.

M. Ressignificando a formação de professores de Química para a Educação

Especial e Inclusiva: uma história de

QNESC2008_8 parcerias. Química nova na escola, São Paulo, n. 30, p. 27-33, 2008.

RIBEIRO, L. T. F.; ARAÚJO, O. H. A. O estágio supervisionado: fios, desafios, movimentos e possibilidades de formação. Revista Ibero-Americana de Estudos REV_IBERO2017_1 em Educação, Araraquara, v. 12, n. 3, p. 1721-1735, 2017.

RODRIGUES, M. A. Quatro diferentes visões sobre o estágio supervisionado. Revista Brasileira de Educação, Rio de Janeiro, v. 18, n. 55, p. 1009- 1034, 2013.

RODRIGUES, M. A. N. Estágio supervisionado e formação de professor: uma reflexão sobre integração teoria e prática. Tear: Revista de Educação EDU2013 1

Ciência e Tecnologia, Canoas, v. 4, n. 2, p. 1-13, 2015.

TEAR2015_1 


\begin{tabular}{|c|c|}
\hline $\begin{array}{l}\text { ROSA, J. K. L. et al. Formação docente: } \\
\text { reflexões sobre o estágio curricular. } \\
\text { Ciência \& Educação, Bauru, v. 18, n. 3, } \\
\text { p. 675-688, } 2012 .\end{array}$ & CIEDU2012_2 \\
\hline $\begin{array}{l}\text { ROSA, M. I. P.; RAMOS, T. A. R. } \\
\text { Memórias e odores: experiências } \\
\text { curriculares na formação docente. Revista } \\
\text { Brasileira de Educação, Rio de Janeiro, } \\
\text { v. } 13 \text {, n. } 39 \text {, p. } 565-575,2008 \text {. }\end{array}$ & $\begin{array}{l}\text { REV_BRA_ } \\
\text { EDU2008_2 }\end{array}$ \\
\hline $\begin{array}{l}\text { ROSO, C. C. et al. Currículo temático } \\
\text { fundamentado em Freire-CTS: } \\
\text { engajamento de professores de Física em } \\
\text { formação inicial. Ensaio Pesquisa em } \\
\text { Educação em Ciências, Belo Horizonte, } \\
\text { v. 17, n. 2, p. 372-389, } 2015 .\end{array}$ & ENSAIO2015_3 \\
\hline $\begin{array}{l}\text { SCHWAHN, M. C. A.; OAIGEN, E. R. O } \\
\text { uso do laboratório de ensino de Química } \\
\text { como ferramenta: investigando as } \\
\text { concepções de licenciandos em Química } \\
\text { sobre o Predizer, Observar, Explicar } \\
\text { (POE). Acta Scientiae, Canoas, v. } 10 \text { n. 2, } \\
\text { p. 151-169, } 2008 .\end{array}$ & ACTA2008_2 \\
\hline $\begin{array}{l}\text { SELINGARDI, G.; MENEZES, V. M. } \\
\text { Prática docente no processo de formação } \\
\text { sob a perspectiva da avaliação formativa. } \\
\text { Ensino, Saúde e Ambiente, Icaraí, v. 10, } \\
\text { n. 3, p. 73-93, } 2017 \text {. }\end{array}$ & $\begin{array}{l}\text { REV_ELET_EN__ } \\
\text { SAÚDE_AMB2017_1 }\end{array}$ \\
\hline
\end{tabular}




\begin{tabular}{|c|c|}
\hline $\begin{array}{l}\text { SHAW, G. S. L.; ROCHA, J. B. T. } \\
\text { Tentativa de construção de uma prática } \\
\text { docente interdisciplinar em Ciências. } \\
\text { Experiências em Ensino de Ciências, } \\
\text { Cuiabá, v. 12, n. 1, p. 95-133, } 2017 .\end{array}$ & EENCI2017_2 \\
\hline $\begin{array}{l}\text { SILVA, V. P. Contribuiç̧ões do estágio na } \\
\text { formação e profissionalização. Ensino } \\
\text { em Re-Vista, Uberlândia, v. 24, n. 2, p. } \\
\text { 344-363, } 2017 \text {. }\end{array}$ & $\begin{array}{l}\text { ENSINO_EM_- } \\
\text { REVISTA2017_2 }\end{array}$ \\
\hline $\begin{array}{l}\text { SILVA, A. L.; TEIXEIRA, O. P. B. } \\
\text { Estágio supervisionado \& imaginário: } \\
\text { a articulação da identidade, da autoria, } \\
\text { das relações de poder e da alteridade } \\
\text { na construção do diário de prática. } \\
\text { Investigações em Ensino de Ciências, } \\
\text { Porto Alegre, v. 21, n. 3, p. 195-215, } 2016 .\end{array}$ & IENCI2016_1 \\
\hline $\begin{array}{l}\text { SILVA, I. P.; NUNES, E. T.; MERCADO, } \\
\text { L. P. L. Experimentos virtuais no estágio } \\
\text { supervisionado de Física. Caderno } \\
\text { Brasileiro de Ensino de Física, } \\
\text { Florianópolis, v. 33, n. 3, p. 1115-1144, } \\
2016 .\end{array}$ & $\begin{array}{l}\text { CAD_BRAS_ENS_ } \\
\text { FÍSICA2016_1 }\end{array}$ \\
\hline $\begin{array}{l}\text { SILVA, A. P. T. B.; BASTOS, H. B. N. } \\
\text { Uma proposta metodológica para o } \\
\text { estágio curricular supervisionado na } \\
\text { EAD: articulações entre CEK e Grupo } \\
\text { Cooperativo. Ciência \& Educação, } \\
\text { Bauru, v. } 23 \text {, n. 3, p. } 741-757,2017 .\end{array}$ & CIEDU2017_6 \\
\hline
\end{tabular}


SILVA, L. E.; SILVA, L. M. O ensino de Ciências na perspectiva da metodologia de aprendizagem por projetos em cursos de licenciatura. Revista Brasileira de RBECT2016_1 Ensino de Ciência e Tecnologia, Ponta Grossa, v. 9, n. 2, p. 237-249, 2016.

SILVA, K. C. M.; MESQUITA, N. A. S. Práxis e Identidade Docente: Entrelaces no Contexto da Formação pela Pesquisa na Licenciatura em Química. Química QNESC2018_4 nova na escola, São Paulo, v. 40, n. 1, p. 44-52, 2018.

SILVA JÚNIOR, A. J.; SILVA, T. P.; SOUZA, R. V. As contribuições do estágio supervisionado para a formação do futuro licenciado em Química: trabalhando conteúdos de química orgânica e de cinética química através de uma abordagem CTSA e experimental.

DEBATES2015_1

Debates em educação, Maceió, v. 7, n. 13, 2015. Disponível em: <http://www. seer.ufal.br/index.php/debateseducacao/ article/view/884/1284>. Acesso em: 25 mai. 2018.

SOUZA, M. L.; CHAPANI, D. T. Aprendizagem da docência: análise de uma proposta de estágio curricular desenvolvida em articulação com o RENCIMA2016_1 programa Novos Talentos - CAPES. Revista de Ensino de Ciências e Matemática, v. 7, n. 1, p. 102-118, 2016. 
SOUSA, I. S. et al. Sistema transversal de ensino-aprendizagem, um desafio no planejamento reflexivo do ensino de Botânica. Areté - Revista Amazônica de ARETÉ2016_4 Ensino de Ciências, Manaus, v. 9, n. 20, p. 176-183, Número especial, 2016.

TESTONI, L. A.; ABIB, M. L. V. S.; AZEVEDO, M. N. Processos criativos didáticos no estágio de futuros professores de física. Revista Ensino \& Pesquisa, União da Vitória, v.15, n.4, p. 60-87, 2017.

TOTTI, F. A.; PIERSON, A. H. C. Compreensões sobre o processo de formação para a docência: concepções de bacharéis e licenciandos sobre a licenciatura em física. Caderno Brasileiro

hb CAD_BRAS_ENS_ FÍSICA2012_2 de Ensino de Física, Florianópolis, v. 29, n. 3, p. 1074-1107, 2012.

ENSINO_E_ PESQUISA2017_2

USTRA, S. R. V.; HERNANDES, C. L. Enfrentamento de problemas conceituais e de planejamento ao final da formação CIEDU2010_5 inicial. Ciência \& Educação, Bauru, v. 16, n. 3, p. 723-733, 2010.

VIEIRA, P. C.; PEREIRA, A. P. S.; MACKEDANZ, L. F. Emprego de experimentos no Ensino Médio para ressignificação dos conceitos de temperatura e calor. Ensino de Ciências e Tecnologia em Revista, Santo Ângelo, v. 1, n. 1, p. 48-52, 2011.

ENCITEC2011_2 


\begin{tabular}{|l|l|}
\hline $\begin{array}{l}\text { VILLANI, F. T. et al. Projeto Tons da Terra: } \\
\text { ensinando Ciências e Química por meio } \\
\text { da produção de tinta de terra amazônica. } \\
\text { Experiências em Ensino de Ciências, } \\
\text { Cuiabá, v. 12, n. 6, p. 252-260, 2017. }\end{array}$ & EENCI2017_5 \\
\hline $\begin{array}{l}\text { VILLANI, A.; FRANZONI, M. A } \\
\text { competência dialógica e a formação de } \\
\text { um grupo 'docente'. Investigações em } \\
\text { Ensino de Ciências, Belo Horizonte, v. } \\
\text { 5, n. 3, p. 191-211, 2000. }\end{array}$ & IENCI2010_3 \\
\hline $\begin{array}{l}\text { WYZYKOWSKI, T.; FRISON, M. D. O } \\
\text { trabalho pedagógico e sua relação com } \\
\text { a constituição da memória: implicações } \\
\text { no ser e no constituir-se professor. } \\
\text { Interfaces da Educação, Paranaíba, v. 6, } \\
\text { n. 18, p. 44-66, 2015. }\end{array}$ & INTERF_DA_- \\
\hline
\end{tabular}

